\title{
Salmonella exploits OmpR to switch essential morphogenetic peptidoglycan synthases in response to intracellular cues
}

\author{
David López-Escarpa, Sónia Castanheira and Francisco García-del Portillo*
}

Laboratory of Intracellular Bacterial Pathogens, National Centre for Biotechnology (CNB)-CSIC.

Darwin 3, 28049 Madrid, Spain

*E-mail: fgportillo@cnb.csic.es

Author Contributions: D.L-E. and F.G-dP. designed research; D.L-E. and S.C. performed research;

D.L-E., S.C. and F.G-dP. analyzed the data; and F.G-dP. wrote the paper.

Competing Interest Statement: The authors declare no competing interest.

Keywords: Salmonella, peptidoglycan, intracellular, OmpR, PBP2, PBP3, PBP2 ${ }_{S A L}$, PBP3 ${ }_{\text {SAL, }}$ acidity, osmolarity, Prc protease 
3 Abstract

Essential peptidoglycan synthases, like penicillin binding proteins 2 and 3 (PBP2/PBP3) of Escherichia coli, define shape by orchestrating cell elongation and division, respectively. Despite being intensively studied as drug targets, the regulatory rules governing their production remain poorly understood. During infection, the closely related pathogen Salmonella enterica serovar Typhimurium downregulates PBP2/PBP3 production and replace them with alternative peptidoglycan synthases, PBP2 ${ }_{S A L} / P B P 3_{S A L}$, absent in E. coli. The bases for such switch in morphogenetic proteins are unknown. Here, we show that the S. Typhimurium regulator OmpR triggers $\mathrm{PBP} 2_{\mathrm{SAL}}$ and $\mathrm{PBP} 3_{\mathrm{SAL}}$ expression responding solely to acid $\mathrm{pH}$ and define a shared motif present in upstream regions of the PBP2 ${ }_{S A L}$ and $P B P 3_{S A L}$ coding genes sufficient for such control. The elimination of PBP2/PBP3 in infection conditions is however multifactorial, requiring acidity, high osmolarity and being favoured by OmpR and the Prc protease. Remarkably, we found that E. coli loses the essential PBP3 required for cell division when exposed to both acidity and high osmolarity, the environmental cues encountered by intracellular S. Typhimurium. Therefore, OmpR played a central role in the evolution of this pathogen when co-opting the regulation of PBP2SAL/PBP3SAL and, consequently, promoting a new morphogenetic cycle that made possible increasing progeny inside acidic eukaryotic phagosomes. 


\section{Significance}

Some enzymes that participate in peptidoglycan metabolism are present exclusively in bacterial pathogens and modify its structure to limit immune recognition. The intracellular pathogen Salmonella enterica serovar Typhimurium is the only example known to date in which a "substitution" of essential peptidoglycan enzymes involved in cell division and elongation takes place during infection. The data presented here support instability of PBP3 in environments with acidity and high osmolarity as a probable selective pressure that promoted the fixation of alternative morphogenetic enzymes. This was possible due to the control that OmpR exerted over these new foreign functions. The acquisition of enzymes like PBP2 $2_{S A L}$ and PBP3 ${ }_{S A L}$ therefore represent a "quantum leap" evolutionary event in S. Typhimurium that made possible the colonization of acidic intracellular niches. 


\section{Introduction}

The peptidoglycan (PG), also known as murein sacculus, marked the evolution of the domain Bacteria as main component of the bacterial cell wall (Egan et al., 2020). It is remarkable among its physicochemical properties the presence of D-amino acids and its assembly as a single giant covalently-bound macromolecule covering the entire cell surface. Based on this, the synthesis and remodelling of its structure are pivotal for determining cell shape and constructing the cell division septum that separates daughter cells (Egan et al., 2017; Egan and Vollmer, 2013). The expansion of the PG along the cell surface has been extensively studied in rod-shaped bacteria like Escherichia coli and Bacillus subtilis, in which the cell elongation and division phases are clearly defined temporally and spatially (den Blaauwen et al., 2008; Errington, 2015; Rohs and Bernhardt, 2021). Both phases are commanded by monofunctional PG synthases with transpeptidase (TP) activity that crosslink stem peptides in parallel glycan chains of the sacculus (den Blaauwen et al., 2017; Szwedziak and Lowe, 2013). This reaction proceeds via recognition of the terminal D-alanine-D-alanine present in the stem peptide of the lipid II precursor molecule, which in $E$. coli is $N$-acetyl-glucosamine- $N$ acetyl-muramyl-L-alanine-D-glutamic acid-meso-diaminopimelic acid-D-alanine-D-alanine (NAG-NAM-L-Ala-D-Glu-m-DAP-D-Ala-D-Ala) (Typas et al., 2011).

In E. coli, the monofunctional PG synthases with TP activity that control cell elongation and cell division are the penicillin-binding proteins 2 and 3 (PBP2 and PBP3), respectively (Egan et al., 2017; Szwedziak and Lowe, 2013). PBP2 and PBP3 form part of multiprotein complexes named elongasome and divisome that have RodA and FtsW as cognate glycosyltransferases (GT). These PBP2-RodA and PBP3-FtsW pairs facilitate the incorporation of the lipid II precursor to the growing PG sacculus during the phases of cell elongation and division (Daitch and Goley, 2020; den Blaauwen and Luirink, 2019; Rohs and Bernhardt, 2021). Importantly, 
the elongasome and divisome are connected to cytoskeletal scaffolds that guide the synthetic machinery to either defined locations along the cylindrical region of the cell or the transversal septum required for division (Cho, 2015; Errington, 2015; McQuillen and Xiao, 2020). Due the important role of these two multiprotein complexes for the morphogenesis and proliferation of bacteria, PBP2 and PBP3 are essential enzymes and have been historically the target of choice for the development of effective beta-lactam antibiotics.

The genome of Salmonella enterica serovar Typhimurium (S. Typhimurium) encodes a pair of PBPs, named PBP2 SAL $_{\text {and }}$ PBP3 ${ }_{S A L}$, which replace PBP2 and PBP3 during the infection of susceptible mice by this intracellular pathogen (Castanheira et al., 2020). PBP2 $2_{\text {SAL }}$ and PBP3 $_{S A L}$ are paralogue enzymes ( $\sim 67 \%$ of identity at the protein level) active in acid $\mathrm{pH}$ and up-regulated by S. Typhimurium after the invasion of eukaryotic cells (Castanheira et al., 2020, 2017). In laboratory media, PBP2sAL and PBP3SAL production is exacerbated in acidified

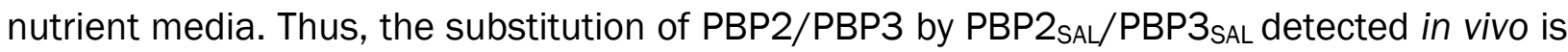
partially reproduced when bacteria grow in acidified media with limited amount of nutrients (Castanheira et al., 2020).

Considering this unprecedented replacement of essential morphogenetic PG enzymes when S. Typhimurium adapts to distinct lifestyles and the stimulation of such phenomenon by intracellular cues like acid $\mathrm{pH}$ and high osmolarity, we sought to dissect the underlying regulatory network responsible for this phenomenon. Here, we show that OmpR is the master regulator that triggers the production of PBP2SAL and PBP3SAL. OmpR was first identified in $E$. coli as modulator of relative levels of major outer membrane proteins like OmpC and OmpF (Taylor et al., 1981) and, subsequently reported to be a positive regulator of the Salmonellapathogenicity island-2 (SPI-2) that modulates the S. Typhimurium intracellular lifestyle (Feng et al., 2003; Garmendia et al., 2003; Lee et al., 2000). OmpR has also been reported to 
control in a positive or negative manner the expression of virulence factors in other pathogens

81 like enterohemorrhagic E. coli (Wang et al., 2021), S. Typhi (Santander et al., 2008), or Vibrio cholerae (Kunkle et al., 2020). Our findings extent this view and catalogue OmpR as a key regulator of PG metabolism and morphogenesis when S. Typhimurium colonizes the 84 intracellular niche of eukaryotic cells. 


\section{Results}

OmpR triggers the expression of PBP2 ${ }_{\mathrm{SAL}}$ and PBP3 ${ }_{\mathrm{SAL}}$ in response to acid $\mathrm{pH}$. To adapt to

the intracellular lifestyle inside acidic vacuoles, S. Typhimurium uses regulators like the two component regulatory systems PhoP-PhoQ, EnvZ-OmpR, PmrA-PmrB and SsrA-SsrB (Chen and Groisman, 2013; Dalebroux and Miller, 2014; Feng et al., 2003; Kenney, 2019; PérezMorales et al., 2017) and the transcriptional regulator SlyA (Buchmeier et al., 1997), among others. PBP2 saL and PBP3 saL production is up-regulated inside host cells (Castanheira et al., 2017), so we sought to determine whether any of these regulators was involved. Null alleles of the genes encoding these regulators were introduced in a S. Typhimurium strain that was 3xFLAG epitope-tagged in the chromosome at the SL1344_1845 and SL1344_1765 genes,

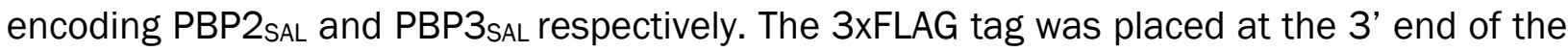
respective coding sequences. Our previous studies show that PBP2SAL-3xFLAG and

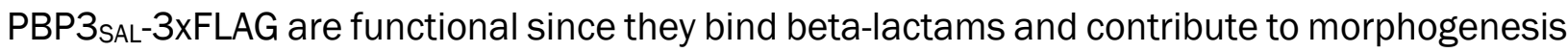
in mutants lacking PBP2 or PBP3 [(Castanheira et al., 2017) and data not shown].

Relative levels of PBP2 SAL-3xFLAG and PBP3 $_{S A L} 3 x$ FLAG (hereinafter referred as PBP2 ${ }_{S A L}$ and PBP3 $_{S A L}$ ) did not change drastically in the isogenic regulatory mutants except for the ompR mutant, which produced almost undetectable levels of both enzymes (Fig. 1A-B), and the phoP and slyA mutants with slightly lesser amounts of PBP2sAL (Fig. 1A). Based on this prominent role of OmpR in controlling production of these PG synthases, we next considered a recent transcriptomic study reporting dacC, encoding the carboxypeptidase PBP6 that trims stem peptides of the PG, as an OmpR-regulated gene in E. coli and S. Typhimurium (Chakraborty and Kenney, 2018). Using chromosomally dacC::3xFLAG-tagged strains, we did not detect such regulation at the protein level with wild type and ompR strains having similar amounts 


\section{synthases PBP1A and PBP1B were detected in response to acid pH (Fig. S1).}
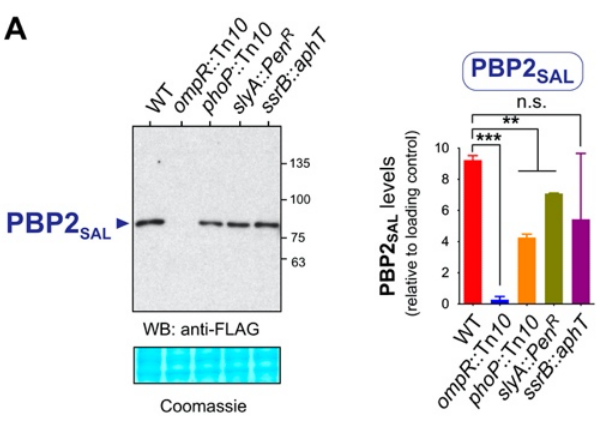

D

C
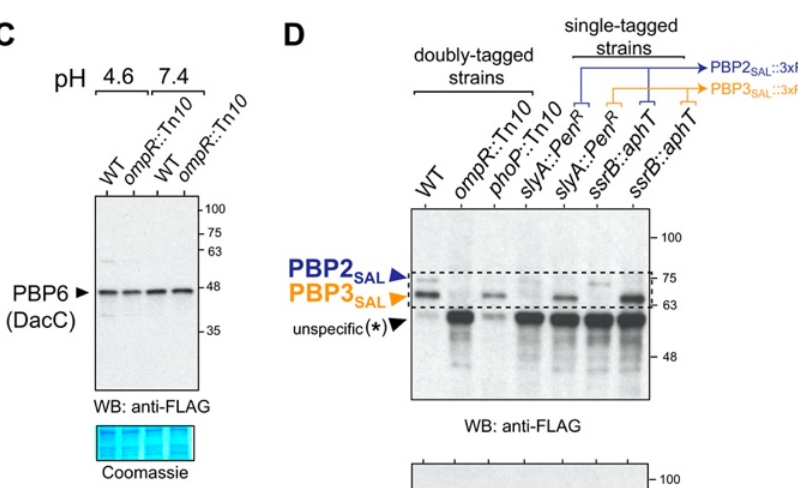

WB: anti-FLAG

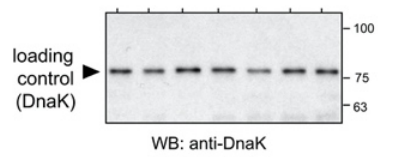

111
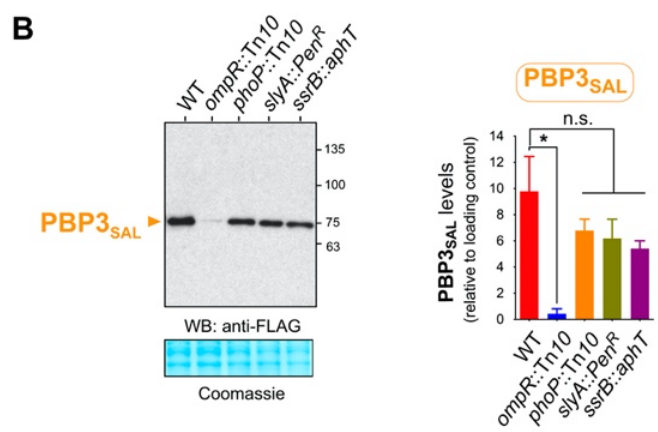

E

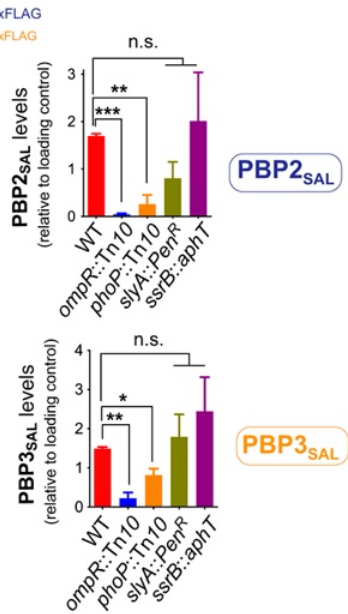

Figure 1. OmpR is the main regulator controlling the production of PBP2sAL and PBP3 SAL $_{\text {in }}$. Typhimurium. (A) Immunodetection of PBP2sAL in total protein extracts of isogenic tagged S. Typhimurium strains bearing a PBP2SAL-3xFLAG allele in its native chromosomal location and mutations in the indicated regulators (OmpR, PhoP, SlyA and SsrB) when growing in LB medium pH 4.6. Shown are also the loading control (Coomassie staining) and the quantification data of the PBP2saL protein levels; (B) Same as for (A) but for isogenic strains bearing a PBP3SAL-3xFLAG allele in its native chromosomal location; (C) Unlike PBP2SAL and PBP3SAL, the levels of the carboxypeptidase PBP6 (DacC) involved in PG metabolism, remain unaltered in the absence of OmpR. For this assay, isogenic strains bearing a dacC::3xFLAG allele in its native chromosomal location were grown in minimal $\mathrm{N}$ medium at the indicated $\mathrm{pH}$ (4.6 or 7.4); (D) Levels of PBP2saL and PBP3saL produced by intracellular S. Typhimurium at $8 \mathrm{~h}$ post-infection of NRK-49F rat fibroblasts. Isogenic wild-type and mutant strains lacking the indicated regulators and either doubly or singly-tagged with the PBP2SAL-3xFLAG and PBP3SAL-3xFLAG alleles in their respective chromosomal locations, were used. DnaK was used as loading control. Data shown in panels $A-D$ are means and standard deviations from a minimum of two independent experiments and statistically analyzed by unpaired parametric t-test. * $P=0.01$ to $0.05 ; * \star, P=0.001$ to 0.01 ; *** $P=0.0001$ to 0.001 ; n.s., not significant; (E) Detection of an unspecific band in both untagged and tagged S. Typhimurium strains in immunoassays with the anti-FLAG antibody when using electrophoresis system based on precast 4-20\% gradient gels required to separate and resolve the positions of PBP2 SAL $_{\text {and PBP3 }}$ SAL (see Materials and Methods). Total protein extracts were prepared from bacteria grown in the indicated minimal (N, PCN), and nutrient rich (LB) media at $\mathrm{pH} 4.6$. 


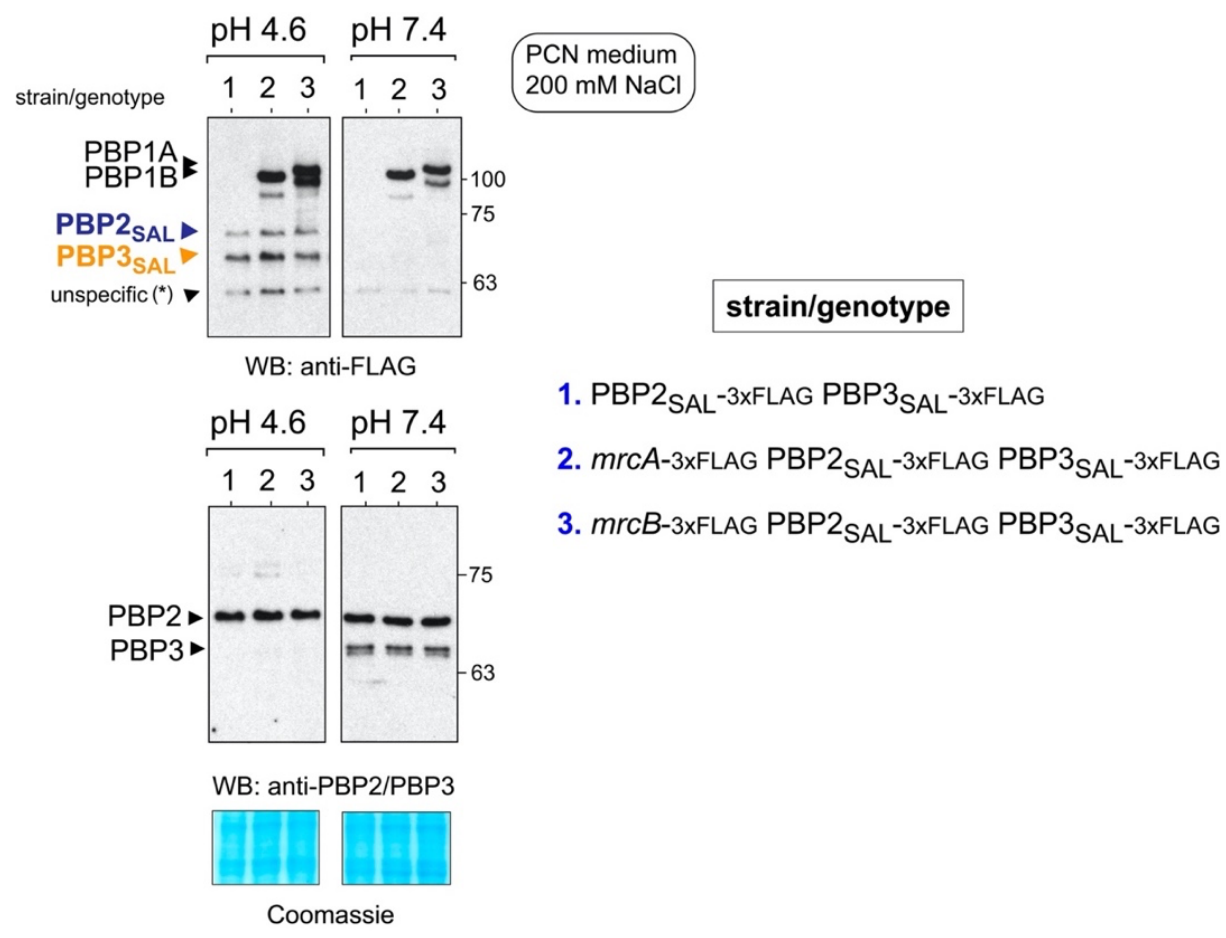

Figure S1. The production of the bifunctional PG synthases PBP1A and PBP1B is not altered by $\mathrm{pH}$ in S. Typhimurium. Shown are western blots of total protein extracts of the indicated chromosomally tagged S. Typhimurium strains grown in PCN medium $200 \mathrm{mM} \mathrm{NaCl}$ at pH values of 4.6 and 7.4. The Coomassie stained membrane is shown as loading control. Note that, unlike PBP1A and PBP1B, the PBP2sAL and PBP3saL enzymes are produced exclusively in acid pH, a condition in which PBP3 is not detected. Data representative of a total of three independent repetitions.

We next determined whether OmpR regulates PBP2 ${ }_{S A L}$ and PBP3 ${ }_{S A L}$ in intracellular S. Typhimurium after invasion of eukaryotic cells (Fig. 1A-B). This was confirmed in cultured

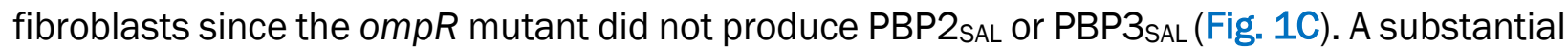
decrease of PBP2 SAL $_{\text {and PBP3 }}$ SAL $(20 \%, 50 \%$ of wild type values, respectively) was observed for the phoP mutant (Fig. 1D). Not statistically significant differences in PBP2 ${ }_{S A L}$ and PBP3 $3_{S A L}$ levels were however found for intracellular bacteria lacking either SlyA or SsrB (Fig. 1D). In some instances, like the analysis performed with extracts prepared from intracellular bacteria, the immunodetection of PBP2SAL-3xFLAG and PBP3SAL-3xFLAG was accompanied by the appearance of a prominent unspecific band (see Fig. 1D). This band was unrelated to PBP2SAL3xFLAG and PBP3SAL-3xFLAG as was also detected in untagged wild type bacteria (Fig. 1E). 
Curiously, this unspecific band was noticeable in protein extracts resolved in precast 4-20\% gradient gels. This type of gel was however the most useful for increasing the difference in the electrophoretic mobilities of PBP2sAL-3xFLAG and PBP3SAL-3xFLAG.

We also examined whether the alternative sigma factors RpoS and RpoE, used by

S. Typhimurium to grow and survive inside host cells (Cano et al., 2001; Chen et al., 1996; Osborne and Coombes, 2009), could regulate PBP2SAL and PBP3 ${ }_{S A L}$ production. Mutants lacking these sigma factors produced however wild type levels of both enzymes (Fig. S2). Taken together, these data indicated that $\mathrm{OmpR}$ is the master regulator that controls the production of PBP2 ${ }_{S A L}$ and $\mathrm{PBP} 3_{\mathrm{SAL}}$ in both acidified laboratory media and inside eukaryotic cells.

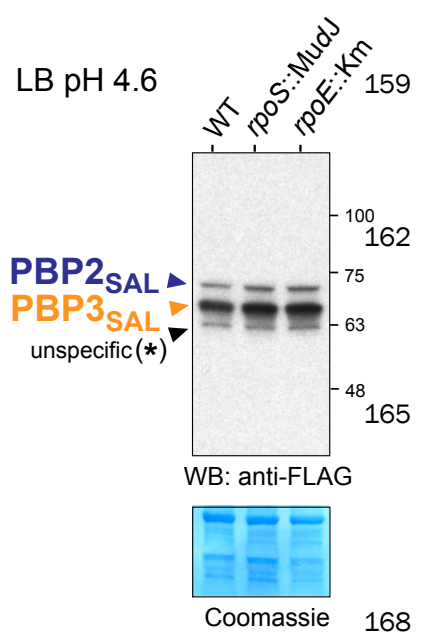

Figure S2. The alternative sigma factors RpoS and RpoE are not required for

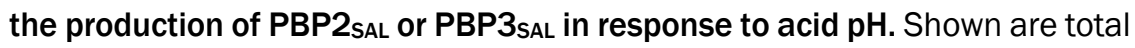
protein extract of isogenic S. Typhimurium wild type and mutant strains defective in RpoS or RpoE grown in LB medium at acid $\mathrm{pH}$ of 4.6. The Coomassie stained membrane is shown as loading control. Data representative of a total of three independent repetitions.

\section{OmpR recognizes sequence motifs located in the upstream region of the genes encoding} PBP2sal and PBP3sal. OmpR binds to target genes by recognizing sequence motifs in the upstream regulatory regions by mechanisms involving relaxation of supercoiled DNA and release of repression mediated by nucleoid binding proteins like H-NS and Fis (Banda et al., 2019; Cameron and Dorman, 2012). ChiP-Seq studies performed in S. Typhimurium and S. Typhi reported TGT(A/T)ACA(A/T) as consensus binding site for OmpR (Perkins et al., 2013). We searched in silico for putative OmpR binding sites in $250 \mathrm{nt}$ upstream regions of 
bioRxiv preprint doi: https://doi.org/10.1101/2021.10.28.466273; this version posted October 28, 2021. The copyright holder for this preprint (which was not certified by peer review) is the author/funder, who has granted bioRxiv a license to display the preprint in perpetuity. It is made available under aCC-BY-NC-ND 4.0 International license.

SL1344_1845 and SL1344_1765, the genes of S. Typhimurium strain SL1344 that encode

PBP2sAL and PBP3sAL respectively. Each of these regions has a putative OmpR-binding site matching the consensus: TGTAACAA in SL1344_1845 (PBP2sAL) and TGTTGCAA in SL1344_1765 (PBP3SAL) (Fig. 2A). The distance of these boxes relative to the start codon is 104 nt for SL1344_1845 and 91 nt for SL1344_1765 (Fig. 2A).

A

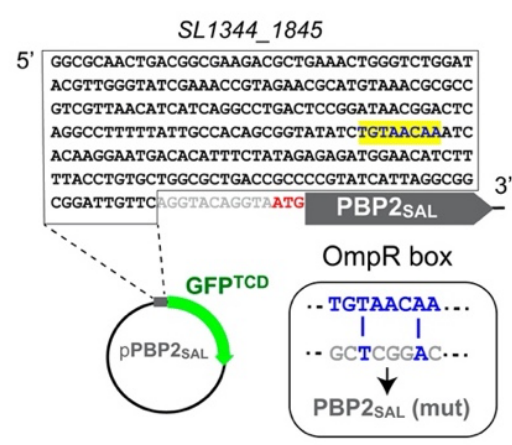

B

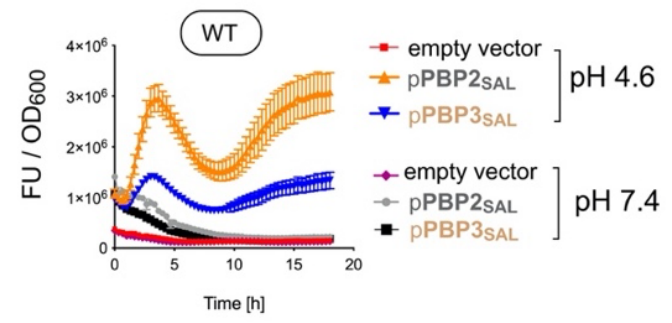

D

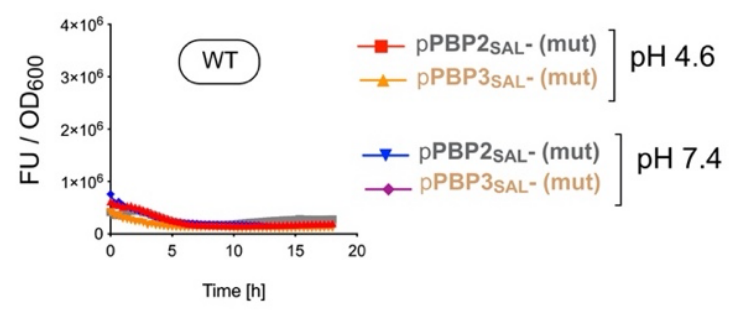

SL1344_1765

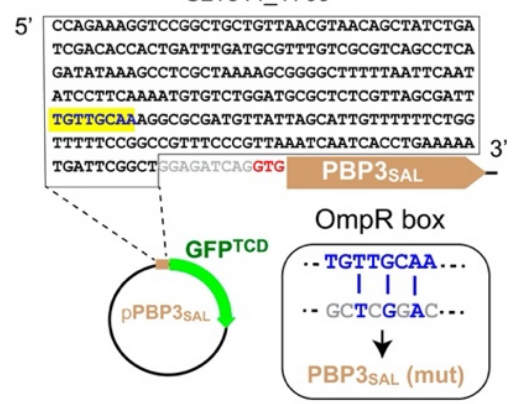

C

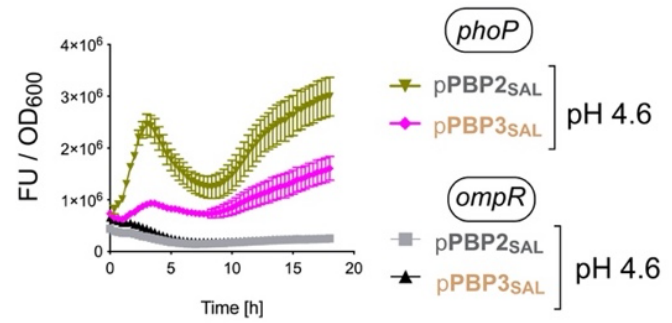

E

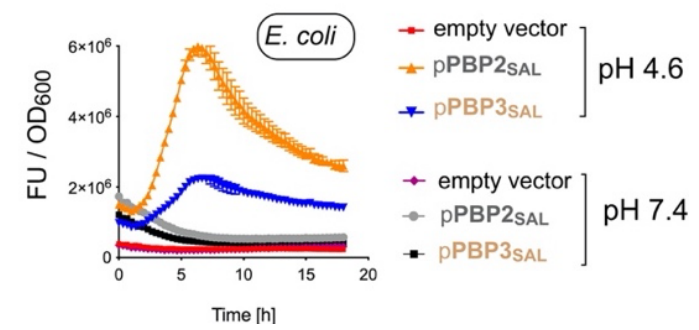

Figure 2. The promoter regions of the S. Typhimurium genes encoding PBP2sAL and PBP3sAL harbor sequences

recognized by OmpR. (A) Upstream regions of the genes encoding PBP2SAL and PBP3sAL that were cloned in the promoter-less reporter plasmid expressing the GFPTCD variant. In yellow are indicated the OmpR boxes analysed and the insets depict the mutated versions (mut) generated in each of the two regions; (B-E) Activity of the PBP2sAL and PBP3sAL promoters in the following strains and growth conditions: (B) wild type S. Typhimurium, PCN medium $200 \mathrm{mM} \mathrm{NaCl}$ at neutral and acid pH (7.4 and 4.6, respectively); (C) isogenic S. Typhimurium mutants lacking either PhoP or OmpR grown in PCN medium 200 mM NaCl pH 4.6; (D) wild type S. Typhimurium bearing reporter constructed based on the mutated (mut) versions of each promoter; and, (E) wild type E. coli expressing the reporter constructs based on the S. Typhimurium PBP2SAL and PBP3SAL promoters. Data were collected automatically during $18 \mathrm{~h}$ in a TECAN plate reader and are represented as the mean and standard deviation from three technical replicates from a representative experiment of a total of three biological replicates. FU, fluorescent units. 
We cloned these $250 \mathrm{nt}$ upstream regions harbouring the putative OmpR binding sites in a promoter-less vector bearing the $g f p^{T C D}$ gene redesigned to reduce $\mathrm{H}-\mathrm{NS}$ transcriptional silencing and having improved translation rate (Corcoran et al., 2010). The upstream regions of PBP2sAL and PBP3 ${ }_{\text {sAL }}$ triggered GFPTCD expression responding to acid $\mathrm{pH}$ and in an OmpR dependent manner albeit independently of PhoP (Fig. 2B-C). We next replaced the putative OmpR boxes identified in the PBP2 ${ }_{\mathrm{SAL}}$ and $\mathrm{PBP} 3_{\mathrm{SAL}}$ upstream regions by a non-functional GCTCGGAC mutated sequence (Fig. 2A), previously reported to abolish OmpR-mediated expression in the S. Typhi tviA gene (Perkins et al., 2013). This mutated sequence resulted in lack of GFPTCD expression (Fig. 2D), therefore indicating that the two sequence motifs identified in silico in the upstream regions of SL1344_1845 (PBP2sAL) and SL1344_1765 204 (PBP3 ${ }_{S A L}$ ) are bona fide OmpR binding sites. The transformation of $E$. coli with the reporter plasmids bearing the wild type OmpR boxes of the PBP2sAL and PBP3 ${ }_{S A L}$ upstream regions led to a similar expression pattern as observed in S. Typhimurium, strictly dependent on acid $\mathrm{pH}$ (Fig. 2E). Altogether, these data showed that S. Typhimurium OmpR triggers expression of PBP2SAL- and PBP3SAL-coding genes recognizing specific sequences in their upstream binding sites and, that this regulation can be recapitulated in E.coli, therefore ruling out the need of Salmonella-specific co-regulators.

OmpR controls the production of PBP2sAL and PBP3 ${ }_{\text {SAL }}$ responding exclusively to acid $\mathrm{pH}$. The EnvZ-OmpR two component system senses acid and osmotic stress to regulate gene expression (Chakraborty and Kenney, 2018). We used minimal defined media to determine whether, in addition to acid $\mathrm{pH}$, other signals such as high osmolarity are required for $\mathrm{PBP} 2_{\mathrm{SAL}}$

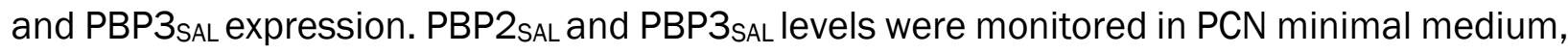
in the presence/absence of $\mathrm{OmpR}, \mathrm{pH}$ values 4.6 and 7.4 and salt concentrations of 0 and $200 \mathrm{mM} \mathrm{NaCl}$. This high amount of salt triggers in E. coli K-12 maximal changes in expression 
of outer membrane proteins further shown to be regulated by OmpR (Alphen and Lugtenberg, 1977; Verhoef et al., 1979). Our control tests showed that $200 \mathrm{mM} \mathrm{NaCl}$ does not affect viability in S. Typhimurium (see below).

The assays in PCN minimal medium showed that acid $\mathrm{pH}$ is the only signal required for triggering PBP2sAL and PBP3 saL production in an OmpR-dependent manner (Fig. 3A). Thus, high salt concentration $(200 \mathrm{mM} \mathrm{NaCl})$ did not increase notoriously the levels of any of the two enzymes (Fig. 3A). Remarkably, we noted that PBP2 and PBP3 levels, which were monitored in parallel in the same samples, decreased drastically when bacteria were exposed to both signals, acid pH of 4.6 and $200 \mathrm{mM} \mathrm{NaCl}$ (Fig. 3A). S. Typhimurium OmpR contributes minimally to the substantial decrease of PBP2 and PBP3 in pH $4.6200 \mathrm{mM} \mathrm{NaCl}$, as only 228 PBP3 levels increased slightly in the absence of this regulator (Fig. 3A).

We next monitored in these minimal media conditions the relative levels of MurF, an essential cytosolic enzyme involved in synthesis of the PG precursor lipid II and that is encoded by a 231 gene mapping downstream of PBP3-encoding gene $\mathrm{ftsl}$. Both murF and $\mathrm{fts} /$ map in the division and cell wall $(d c w)$ gene cluster that functions as a single polycistronic transcriptional unit (Fig. 3B). Unlike PBP3, MurF levels did not show substantial changes in response to acid $\mathrm{pH}$ 234 and/or high osmolarity, and with no effect for the presence/absence of OmpR (Fig. 3C). Collectively, these observations sustain post-transcriptional negative regulation acting specifically on PBP3 when S. Typhimurium encounters acid pH and high osmolarity. Likewise, the data show that upregulation of $\mathrm{PBP} 3_{\mathrm{SAL}}$, triggered solely by acid $\mathrm{pH}$, differs from the elimination of PBP3, which requires both acidity and high osmolarity. 
A

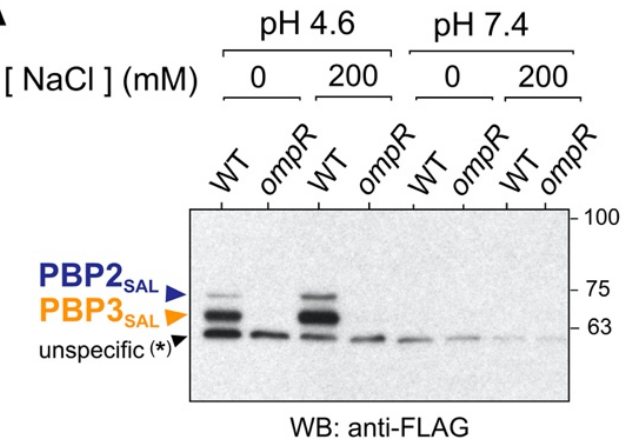

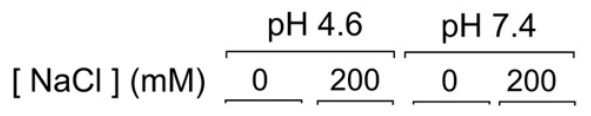

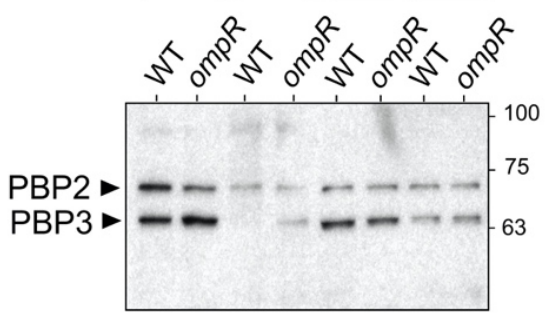

WB: anti-PBP2/PBP3
B S. Typhimurium / E. coli

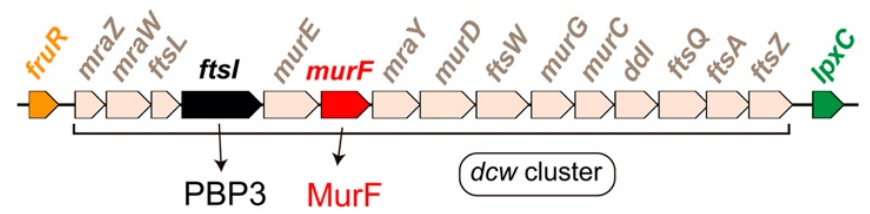

C
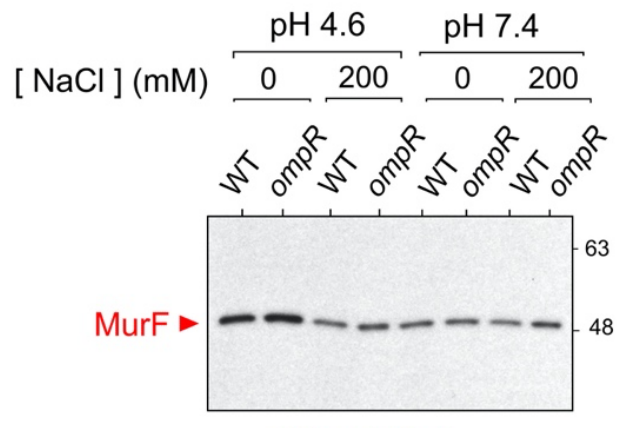

WB: anti-MurF

Coomassie

Figure 3. Acid pH and high osmolarity signal S. Typhimurium for the precise loss of PBP3. (A) Levels of the enzymatic pairs PBP2SAL/PBP3SAL and PBP2/PBP3 detected in total protein extracts of S. Typhimurium wild type and ompR strains grown in PCN minimal medium at distinct $\mathrm{pH}$ (4.6 and 7.4) and osmolarity $(0,200 \mathrm{mM} \mathrm{NaCl})$. A Coomassie staining of the membrane used in the immunoassays is shown as loading control; (B) Detail of the division and cell wall (dcw) gene cluster that is conserved in E. coli and S. Typhimurium and functions as an multicistronic operon linked at the transcriptional level. The relative positions of the gene ftsl, encoding PBP3, and murF, encoding a cytosolic enzyme involved in the synthesis of the PG precursor lipid II, are indicated. (C) MurF levels detected in the total protein extracts used for the determination of PBP2SAL/PBP3 ${ }_{\mathrm{SAL}}$ and PBP2/PBP3 levels as shown in panel (A). Note that, unlike PBP3, the relative levels of MurF do not drop substantially in high osmolarity and acid $\mathrm{pH}$.

\section{OmpR allows S. Typhimurium to divide in an acidic environment with high osmolarity. Since} PBP3 is required for cell division, we reasoned that its elimination without having PBP3 ${ }_{S A L}$ as counterpart could lead to blockage of such essential process in the cell cycle. This phenotype was expected for the S. Typhimurium ompR mutant, which only shows trace amounts of PBP3 when growing in minimal medium pH 4.6 and $200 \mathrm{mM} \mathrm{NaCl}$ (Fig. 3A). We also sought to 
determine whether E.coli, which has an absolute requirement of PBP3 for division, could negatively regulate its production if exposed to acid $\mathrm{pH}$ and high osmolarity. Surprisingly, western blot analyses showed that E. coli K-12 strain MG1655, as S. Typhimurium, loses PBP3 when growing in minimal medium at pH 4.6 and $200 \mathrm{mM} \mathrm{NaCl}$ (Fig. 4A). The loss of PBP3 impacted the cultivability of both S. Typhimurium ompR mutant and E. coli MG1655 in acid $\mathrm{pH}$ and high osmolarity although both strains displayed similar growth rate in liquid culture compared to wild type bacteria (Fig. 4B). This latter observation suggested that acidity and high osmolarity did not affect increase in cell mass but promoted a selective loss of PBP3. Such conclusion was further supported by microscopy, which showed that the S. Typhimurium ompR mutant and wild type E. coli MG1655 strains do not divide properly when growing in $\mathrm{pH}$ 4.6 and $200 \mathrm{mM} \mathrm{NaCl}$ (Fig. 4C). Collectively, these results unveiled the key role that OmpR plays in S. Typhimurium for colonizing acidic niches with high osmolarity by inducing the expression of an alternative PG enzyme, PBP3saL, capable of promoting cell division under those conditions (Castanheira et al., 2017).

\section{The two-component system PhoP-PhoQ does not contribute to the switch of the} an important regulator modulating the adaptation of S. Typhimurium to the intra-phagosomal lifestyle in response to signals like acid pH (Martin-Orozco et al., 2006) and micromolar levels of the divalent cation magnesium (García Véscovi et al., 1996). In extracellular conditions, the S. Typhimurium phoP mutant showed a slight decrease in the levels of PBP2 $2_{\mathrm{SAL}}$ when growing in acidified LB medium ( $\mathrm{pH} 4.6$ ) and in those of both enzymes, PBP2 ${ }_{\mathrm{SAL}}$ and PBP3 ${ }_{\mathrm{SAL}}$, when 279 infecting fibroblasts (Fig. 1A, 1D). 
A

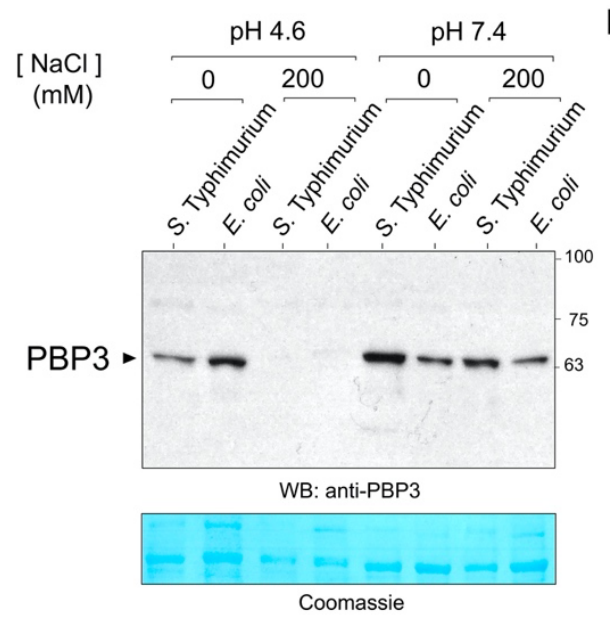

B
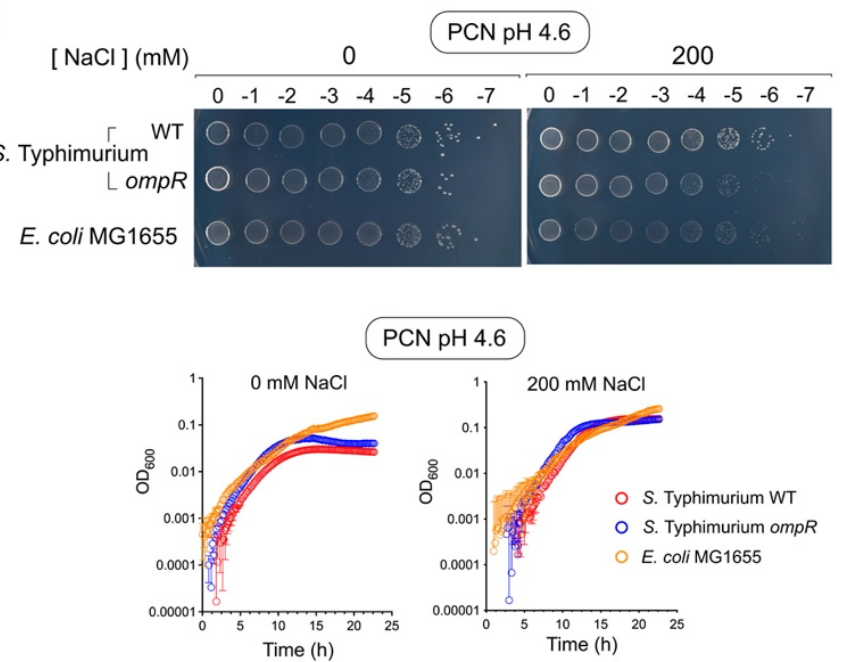

C

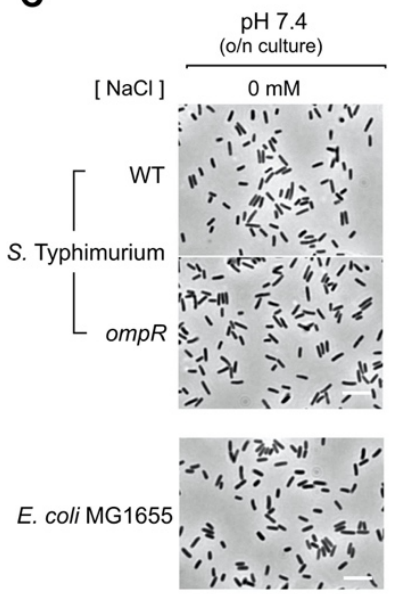

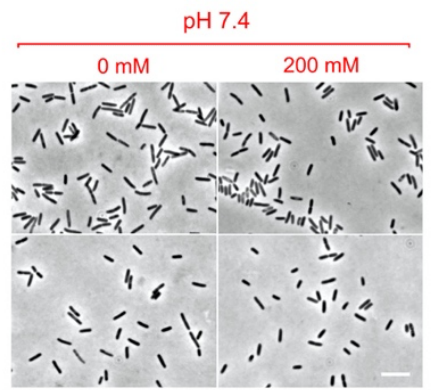

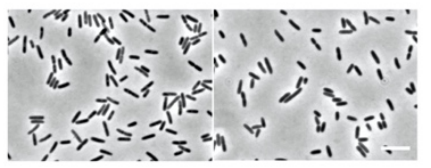

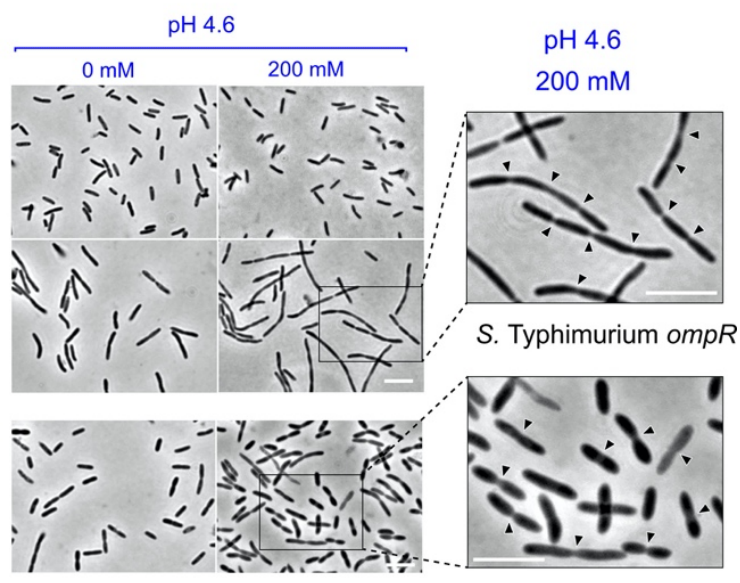

E. coli MG1655

Figure 4. The net production of PBP3 in acid pH and high osmolarity is arrested in both S. Typhimurium and

E. coli. (A) Comparison of PBP3 levels determined in total protein extracts of S. Typhimurium and E. coli wild type strains grown in PCN minimal medium at the indicated $\mathrm{pH}$ and osmolarity. Note the marked decrease of the enzyme in bacteria exposed to acid $\mathrm{pH}$ and high osmolarity; (B) Cultivability of S. Typhimurium (wild type and ompR strains) and E. coli MG1655 wild type on plates of PCN minimal medium at pH 4.6 and the indicated osmolarity $(0,200 \mathrm{mM} \mathrm{NaCl})$. Shown are serial dilutions of an overnight culture obtained in PCN medium $0 \mathrm{mM}$ $\mathrm{NaCl} \mathrm{pH} \mathrm{7.4.} \mathrm{Included} \mathrm{are} \mathrm{also} \mathrm{the} \mathrm{growth} \mathrm{curves} \mathrm{of} \mathrm{three} \mathrm{strains} \mathrm{in} \mathrm{liquid} \mathrm{PCN} \mathrm{medium} \mathrm{pH} 4.6$ with low or high osmolarity (0 or $200 \mathrm{mM} \mathrm{NaCl}$, respectively); (C) Microscopy observation of S. Typhimurium (wild type and ompR strains) and E. coli MG1655 after growing in PCN medium for $4 \mathrm{~h}$ at the indicated $\mathrm{pH}$ and osmolarity. The inoculum was in all cases obtained in PCN medium pH 7.4, $0 \mathrm{mM} \mathrm{NaCl}$. Shown are also enlargements of $S$. Typhimurium ompR and wild type E. coli MG1655 cell in acid pH (4.6) and high osmolarity displaying morphological alterations consistent with the loss of PBP3 and, consequently, with the arrest of the cell division process. The arrowheads point to cell division sites in which a small constriction is observed, compatible with the loss of PBP3. Bar, $5 \mu \mathrm{m}$. Data shown are representative of a minimum of three independent biological replicates. 


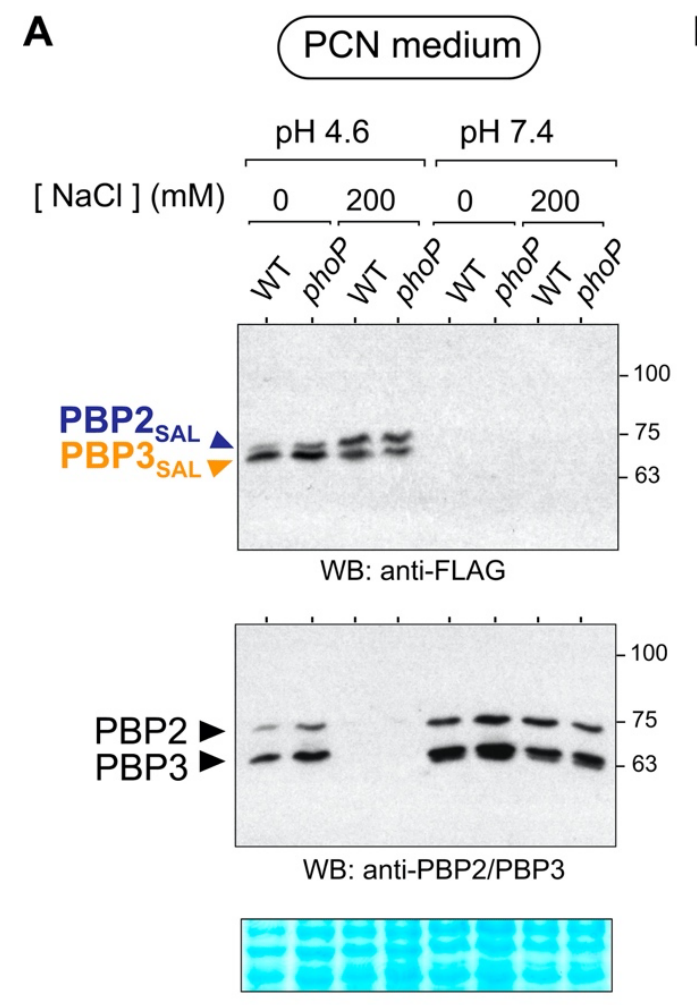

Coomassie

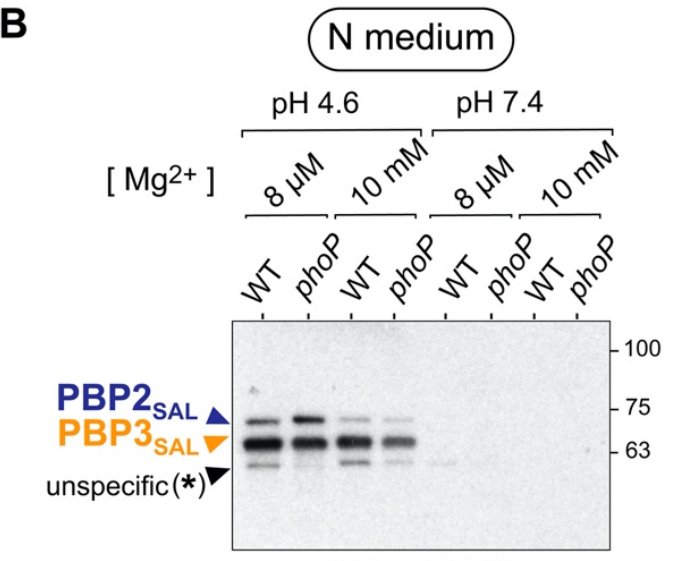

WB: anti-FLAG

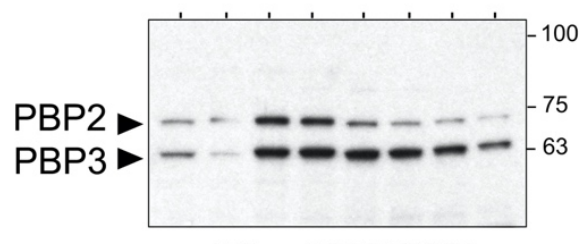

WB: anti-PBP2/PBP3

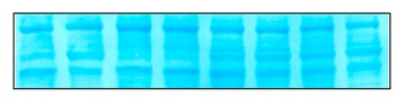

Coomassie

Figure 5. Acid $\mathrm{pH}$ and limited amount of magnesium signal $\mathrm{S}$. Typhimurium to replace PBP2/PBP3 by PBP2sAL/PBP3 sAL $_{\text {in }}$ a PhoP-independent manner. (A) Levels of the pair of enzymes PBP2/PBP3 and PBP2SAL/PBP3SAL present in total protein extracts of $S$. Typhimurium wild type and phoP isogenic strains grown in PCN minimal medium at the indicated pH and osmolarity; (B) same as in (A) but in bacteria grown in $\mathrm{N}$ minimal media at two different $\mathrm{pH}$ (4.6 and 7.4) and magnesium concentrations ( $8 \mu \mathrm{M}$ and $10 \mathrm{mM}$ ). Note that the condition with low magnesium concentration and acid pH triggers the loss of PBP2 and PBP3 while the production of PBP2SAL and PBP3SAL increases notoriously. Data shown are representative of a minimum of three independent biological replicates.

Based on these data, we monitored the levels of PBP2/PBP3 and PBP2SAL/ PBP3 $3_{S A L}$ in in parameters such as: i) pH (acid 4.6, neutral 7.4); ii) osmolarity (0, $200 \mathrm{mM} \mathrm{NaCl);} \mathrm{or,} \mathrm{iii)}$ magnesium concentrations $(8 \mu \mathrm{M}, 10 \mathrm{mM})$. None of these variables showed a PhoPdependent regulatory mechanism on any of the four PBPs examined (Fig. 5A-B). Interestingly, the levels of PBP2 and PBP3 dropped in acid pH (4.6) at low magnesium concentration ( $8 \mu \mathrm{M})$ (Fig. 5B), but this change took place independently of PhoP. Taken together, these data ruled 
out a contribution of the PhoP-PhoQ system in the switch of essential morphogenetic PG synthases occurring when S. Typhimurium is exposed to an acidified medium with high osmolarity.

The protease Prc targets PBP3 and PBP3 ${ }_{S A L}$ in the morphogenetic switch and in a pHdependent manner. In E. coli, the protease Prc processes the C-terminal region of PBP3 (Hara et al., 1989; Nagasawa et al., 1989) having as additional substrates other enzymes related to PG metabolism such as the endopeptidase MepS (Spr) (Singh et al., 2015) and the murein transglycosylase MltG (Hsu et al., 2020). The cleavage site recognized by Prc in the PBP3 of E.coli (588 residues) is valine-577 (V577) (Nagasawa et al., 1989). Interestingly, this V577 residue is conserved in the PBP3 of S. Typhimurium, and the orthologue PBP3 $3_{\mathrm{SAL}}$, of 581 aa, has also a valine located 11 residues apart of the C-terminus, concretely V570 (Castanheira et al., 2017). To test whether Prc targets any of these two PBPs in S. Typhimurium, we determined levels of the precursor and the processed forms of PBP3 and PBP3 SAL $_{\text {in }}$ wild type and $\Delta$ prc strains, including also in parallel wild type E. coli as additional control.

In acid $\mathrm{pH}(4.6)$ and no salt added $(0 \mathrm{mM} \mathrm{NaCl})$, the absence of Prc resulted in S. Typhimurium 333 in decreased levels of PBP3 (Fig. 6A) whereas in E. coli it was clear the presence of two bands, the precursor and mature forms of PBP3 (Fig. 6A). Interestingly, PBP3 is not processed by S. Typhimurium under these conditions ( $\mathrm{pH} \mathrm{4.6,0} \mathrm{mM} \mathrm{NaCl)} \mathrm{(Fig.} \mathrm{6A).} \mathrm{As} \mathrm{expected,} \mathrm{no} \mathrm{PBP3}$ was visualized in any of the strains tested at pH 4.6, $200 \mathrm{mM}$ (Fig. 6A). At neutral pH 7.4, both PBP3 forms (precursor, mature) were visible in S. Typhimurium wild type cells whereas only the full length PBP3 was detected in the $\Delta$ prc mutant (Fig. 6B). This result unequivocally showed that Prc of S. Typhimurium also cleaves PBP3, but only at neutral pH (compare Fig. 6A and 6B). The capacity of S. Typhimurium Prc to cleave PBP3 in neutral pH of 7.4 was OmpR-independent regardless of the osmolarity used (Fig. 6C). 
A

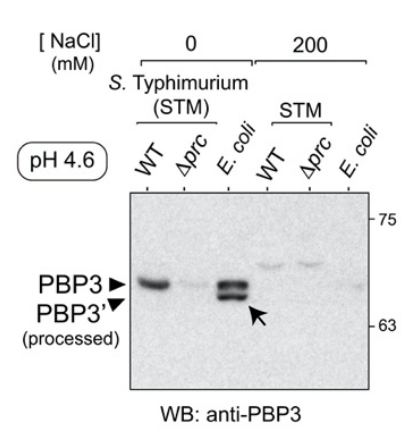

D
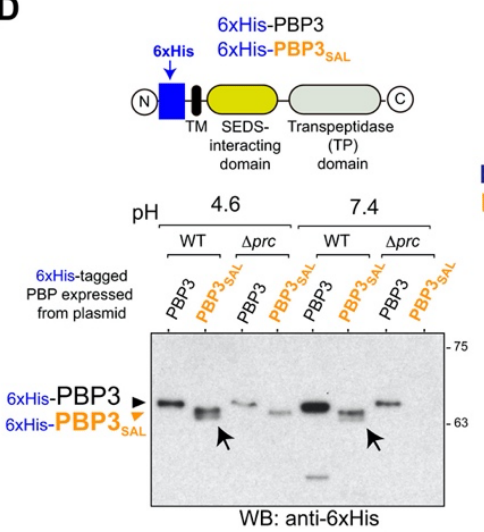

B

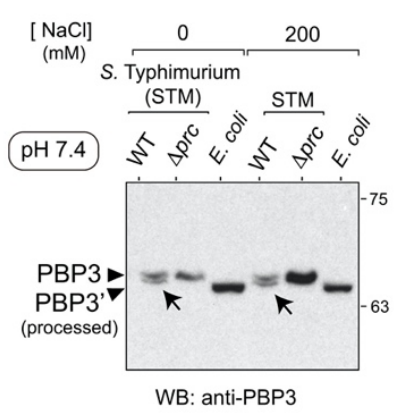

C
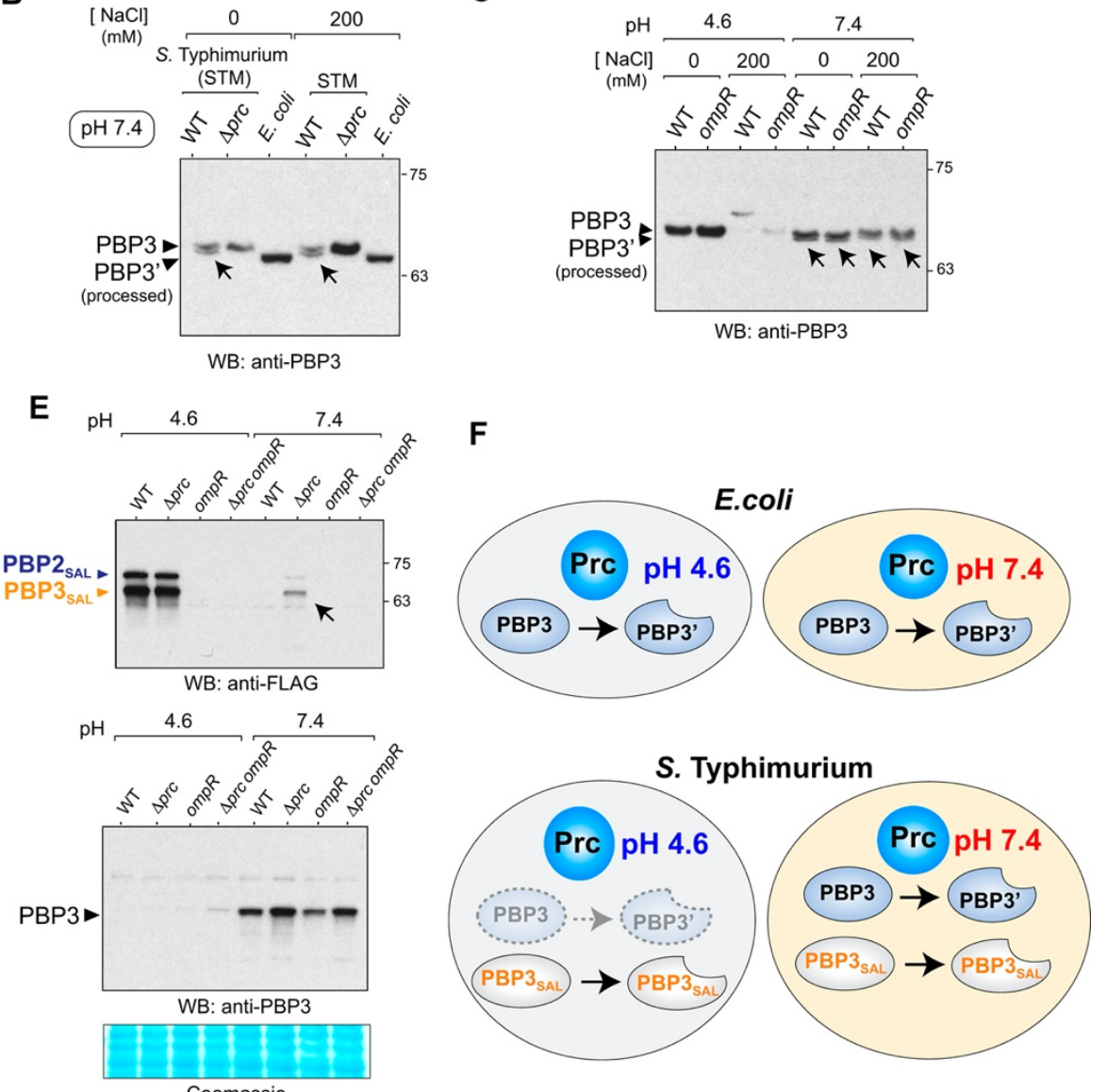

Figure 6. S. Typhimurium exploits the protease Prc to target selectively PBP3 or PBP3sAL at distinct pH. (A) Processing of PBP3 is not observed in wild type S. Typhimurium at acid pH (4.6) whereas this PBP3 is cleaved

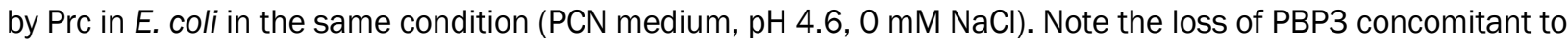
the increase in osmolarity $(200 \mathrm{mM} \mathrm{NaCl})$ and the loss of PBP3 in the S. Typhimurium $\Delta$ prc mutant at low osmolarity. Arrow indicates the mature processed form of PBP3; (B) S. Typhimurium Prc cleaves PBP3 at neutral $\mathrm{pH}(7.4)$ irrespective of the amount of salt added to the medium $(0,200 \mathrm{mM} \mathrm{NaCl})$. The PBP3 form observed for $E$. coli in these assays is processed as inferred from its higher electrophoretic mobility. Arrows point to the processed mature form of PBP3; (C) The protease activity of S. Typhimurium Prc over PBP3 at neutral pH (7.4) occurs independently of OmpR and osmolarity. Arrows point to the processed mature form of PBP3; (D) Prc cleaves a 6xHis variant of PBP3saL tagged at the N-terminus expressed from plasmid at both, acid (4.6) and neutral (7.4) pH. Arrows point to the processed form of PBP3saL. Unlike the case of 6xHis-PBP3saL and the PBP3 expressed from its native chromosomal location [see panel (B)], the 6xHis-PBP3 tagged variant expressed from plasmid is not cleaved by Prc; (E) Detection of minor amounts of PBP2SAL/PBP3sAL at neutral pH in the absence of Prc (arrow), may indicate the existence a quality control exerted by this protease at this $\mathrm{pH}$; $(\mathbf{F})$ Diagram depicting the preferred recognition of S. Typhimurium for PBP3 ${ }_{\mathrm{SAL}}$ at acid $\mathrm{pH}$ and for PBP3 at neutral $\mathrm{pH}$ although also showing the capacity of the protease to target PBP3saL if produced at neutral pH. 
With regards to PBP3SAL and considering the presence of a residue V570 putatively recognized by Prc, we assessed whether it could be cleaved by this protease at the C-terminus. To this aim, we used PBP3SAL and PBP3 versions bearing a 6xHis tag at the N-terminus (Castanheira et al., 2020). These two variants, 6xHis-PBP3 and 6xHis-PBP3sAL, were expressed from plasmid in wild type and $\Delta$ prc strains at acid ( $\mathrm{pH} \mathrm{4.6)}$ and neutral (7.4) pH (Fig. 6D). These assays showed that Prc cleaves $6 \mathrm{xHis}^{-\mathrm{PBP}} 3_{\mathrm{SAL}}$ at the $\mathrm{C}$-terminus at both $\mathrm{pH}$ whereas no processing was observed for 6xHis-PBP3 (Fig. 6D). This result in PBP3 suggests that the modification at the N-terminus of this enzyme, which faces the cytosol, could alter its recognition in the periplasm by the protease, an effect not seen in unmodified PBP3 (Fig. 6B).

Given the capacity of Prc to cleave the C-terminus of PBP3SAL (Fig. 6D), we assessed whether this protease could play a role in S. Typhimurium in preventing the presence of this enzyme when the pathogen grows in neutral $\mathrm{pH}$. The lack of Prc resulted in the detection of a small amount of PBP3 SAL $_{\text {a }}$ at 7.4 (Fig. 6E). The detection of these low amounts of PBP3 $3_{S A L}$ at neutral $\mathrm{pH}$ in the absence of the protease was, however, OmpR-dependent (Fig. 6E). Taken 375 together, these data demonstrated that PBP3 and PBP3 ${ }_{S A L}$ are substrates of Prc in S. Typhimurium although with a clear dependence on the $\mathrm{pH}$. Thus, whereas Prc cleaves PBP3 only at neutral $\mathrm{pH}$, it processes $\mathrm{PBP}_{\mathrm{SAL}}$ in both the physiological condition in which its production is triggered by OmpR (acid $\mathrm{pH}$ of 4.6) and in neutral $\mathrm{pH}$. Unlike Prc of S. Typhimurium, this protease in E. coli cleaves PBP3 at both acid and neutral pH (Fig. 6F). 


\section{Discussion}

Morphogenesis has been mostly investigated in bacteria exhibiting rod or coccoid shapes in defined (controlled) environmental conditions (Daitch and Goley, 2020; Egan et al., 2020;

Radkov et al., 2018) and in organisms exhibiting morphological plasticity (Caccamo and Brun, 2018). These latter include those generating differentiated cells, subcellular structures like stalks and branching or curved shapes (Caccamo and Brun, 2018; Khanna et al., 2020). The PG determines cell shape and some studies demonstrate that specific enzymes acting on this macromolecule are responsible for morphological plasticity (Caccamo and Brun, 2018). Inversely, S. enterica serovar Typhimurium represents what to our knowledge is the only case known to date involving two morphogenetic machineries with distinct PG synthases (PBP2/PBP3 and PBP2sAL/PBP3 ${ }_{S A L}$ ) to generate the same (rod) cell shape.

To get insights into how S. Typhimurium regulates this switch of morphogenetic machineries, we initially inspected expression levels of the PBP2SAL- and PBP3 SAL-encoding genes SL1344_1845 and SL1344_1765 in transcriptomic datasets. Data obtained from bacteria infecting cultured macrophages (Eriksson et al., 2003), fibroblasts (Núñez-Hernández et al., 2013), epithelial cells (Hautefort et al., 2008) or exposed to varied stress conditions in laboratory media (Kroger et al., 2013), indicated that these two genes are poorly transcribed in all conditions tested. Only in a few cases, increased transcription, in the order of 3-fold, was registered for the $\mathrm{PBP}_{\mathrm{SAL}}$-encoding gene in bacteria recovered from macrophages or exposed to high salt (0.3 M NaCl, $10 \mathrm{~min})$, acid (pH 5.8) or bile (3\% bile, $10 \mathrm{~min}$ ) (Kroger et al., 2013). This reduced transcriptional activity contrasts with the relatively high amounts of PBP2 ${ }_{\text {SAL }}$ and PBP3 $_{\text {SAL }}$ that are detected by western blot [(Castanheira et al., 2020, 2017), this study]. Our data unequivocally show that OmpR controls the production of these two PG enzymes and that acid $\mathrm{pH}$ is necessary and sufficient for such positive regulation. OmpR, which was first 
identified as a regulator of the levels of the two major outer membrane proteins, OmpC and OmpF (Taylor et al., 1981), was latter shown to control these porins via regulatory small RNAs (sRNAs) like MicF and MicC that target the ompF and ompC transcripts, respectively (Vogel and Papenfort, 2006). OmpR induces transcription of two other sRNAs, OmrA and OmrB, which control post-transcriptionally the stability of multiple mRNA, including the ompR-envZ transcript as a feedback auto-regulatory loop (Brosse et al., 2016). Therefore, a recurrent theme in the mechanisms that $\mathrm{OmpR}$ uses as regulator is the simultaneous action at transcriptional and post-transcriptional levels by controlling transcription of the target mRNA and SRNA that will regulate post-transcriptionally such target (Brosse et al., 2016). In this scenario, it is tempting to speculate on sRNAs modulating the stability and/or translation of the mRNAs encoding PBP2 SAL $_{\text {and }}$ PBP3 ${ }_{S A L}$, a possibility that merits to be investigated in future work.

When compared to other virulence-related regulators, it is clear that OmpR plays a master role in controlling the production of PBP2 ${ }_{S A L}$ and PBP3 $3_{S A L}$, both in laboratory media and inside host cells. This regulation could be coordinated with that PhoP may exert on PBP2SAL in extracellular bacteria (Fig. 1A) or in intracellular bacteria for the case of PBP2SAL and PBP3SAL (Fig. 1D). OmpR and PhoP control expression of horizontally acquired foreign genes and crosstalk in regulating SPI-2, the key pathogenicity island exploited by S. Typhimurium for a successful intracellular infection (Fass and Groisman, 2009; Kim and Falkow, 2004; Lee et al., 2000; Liew et al., 2019; Worley et al., 2000). Our results, however, show that SsrB, absolutely required for expression of SPI-2 genes, plays no role in the production of PBP2SAL and PBP3 ${ }_{S A L}$. This finding suggests that PBP2SAL/PBP3 ${ }_{S A L}$ and SPI-2 might be independent targets in the $\mathrm{OmpR}$ and PhoP regulons. The data obtained with the transcriptional reporter fusions showed that OmpR acts canonically on the SL1344_1845 and SL1344_1765 
promoters recognizing sequences that match the consensus TGTWACAW (Perkins et al., 2013). The OmpR box present in the promoter of the PBP3SAL-encoding gene has a mismatch respect the consensus, $\mathrm{G}$ in fifth position (TGTTGCAA), which may explain why its reporter was expressed at lower levels than that of PBP2sAL (Fig. 2). Importantly, the expression of these reporters was independent of PhoP. Based on these findings, the positive regulation that PhoP may exert on PBP2sAL and PBP3SAL could be indirect, e.g. via regulatory sRNAs targeting the respective mRNAs. Another relevant finding in these assays was the reproducibility of the reporter expression pattern in a heterologous system of E. coli, showing the same dependence on acid pH as in S. Typhimurium. Based on these findings, we therefore conclude that $0 \mathrm{mpR}$ binding to the PBP2 $2_{\mathrm{SAL}}$ and $\mathrm{PBP} 3_{\mathrm{SAL}}$ promoters is $\mathrm{pH}$-sensitive.

Acid $\mathrm{pH}$ and high osmolarity are signals perceived by the sensor EnvZ to activate OmpR (Chakraborty and Kenney, 2018; Kenney, 2019; Quinn et al., 2014). Genome-wide expression analyses show that each signal by separate triggers only partly-overlapping OmpR regulons (Chakraborty and Kenney, 2018). Our analyses of PBP2sAL and PBP3 ${ }_{S A L}$ at the protein level supports this view since acid $\mathrm{pH}$ of 4.6 as single signal is sufficient to detect high levels of the two enzymes. Low magnesium levels in the order of micromolar, known to signal the sensor PhoQ to activate PhoP, are however not required for PBP2 SAL $_{\text {and }}$ PBP3 ${ }_{S A L}$ production (Fig. 5B). These data are consistent with a regulation of PBP2 SAL and PBP3 ${ }_{\text {SAL }}$ triggered essentially by acidification of the cytoplasm mediated by the transcriptional regulator OmpR (Kenney, 2019). Cytoplasm acidification is known to stimulate the cytoplasmic domain of the sensor PhoQ leading to increased expression of PhoP-activated genes (Choi and Groisman, 2016), 450 some of which could be potentially linked to ensure the required levels of PBP2SAL and PBP3saL, especially in response to intracellular cues (Fig. 1D). 
We were also much interested in getting insights into how S. Typhimurium diminishes PBP2 and PBP3 levels in infection conditions given these are essential enzymes in E. coli. The elimination of PBP2 and PBP3 was probably crucial in evolutionary terms by acting as selective force that facilitated the fixation of a second morphogenetic machinery, fully active in acid $\mathrm{pH}$ and high osmolarity. To recall that in the laboratory the complete replacement of

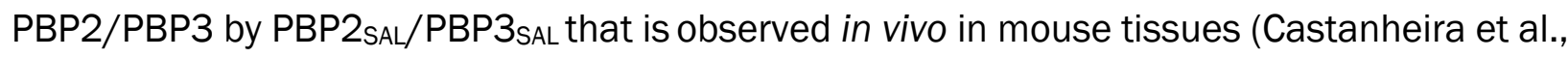
2020) is only partially reproduced when using the acidified PCN medium. This is more notorious for PBP2, for which a small amount of the enzyme is still detected in acid pH despite the de novo synthesis of PBP2 sAL. Fortunately, that was not the case for PBP3/PBP3 $_{\mathrm{SAL}}$, in which the acidified PCN medium with high amount of salt (200 mM NaCl) led to a complete interchange of both enzymes in S. Typhimurium. We are currently taking caution about this coexistence of morphogenetic enzymes since in certain media, as an acidified nutrient rich LB medium, both sets of enzymes (PBP2/PBP2 ${ }_{\text {SAL }}$ and PBP3/PBP3 SAL $_{\text {) }}$ are detected at similar levels (Castanheira et al., 2017), a situation that might not occur in natural habitats colonized by this pathogen.

The data presented here also implicate OmpR in the elimination of PBP2 and PBP3 in response to acid $\mathrm{pH}$ although, in this case, additional regulatory factors like high osmolarity, the periplasmic protease Prc and a low concentration of $\mathrm{Mg}^{2+}$ were equally involved (Fig. 7). Surprisingly, this intricate "negative" regulatory network is conserved in E. coli, at least for PBP3, as this organism loses this enzyme and is unable to divide if exposed to acid pH (4.6) and $200 \mathrm{mM} \mathrm{NaCl}$. Intriguingly, uropathogenic E. coli (UPEC) undergoes filamentation during urinary tract infections as a strategy to subvert host immune defences (Horvath et al., 2011; Justice et al., 2008, 2006). This rod-to-filament morphological transition is stimulated during the intracellular stage, in which probably bacteria are exposed to an acid environment. A 
recent study in E. coli has also provided evidence of an SRNA, FtsO, mapping internally to the

PBP3-encoding gene ftsI (Adams et al., 2021). Despite not knowing how FtsO is generated, it modulates the levels of the ompC transcript via the sRNA RybB, and its presence supports the existence of a post-transcriptional regulatory mechanism that could act specifically to regulate PBP3 levels concomitantly to those of the outer membrane protein OmpC. The loss of PBP3, detectable also in E. coli, underscores how relevant was for S. Typhimurium the acquisition of PBP3 $_{S A L}$ to colonize eukaryotic acidic phagosomes ensuring the maintenance of the progeny.

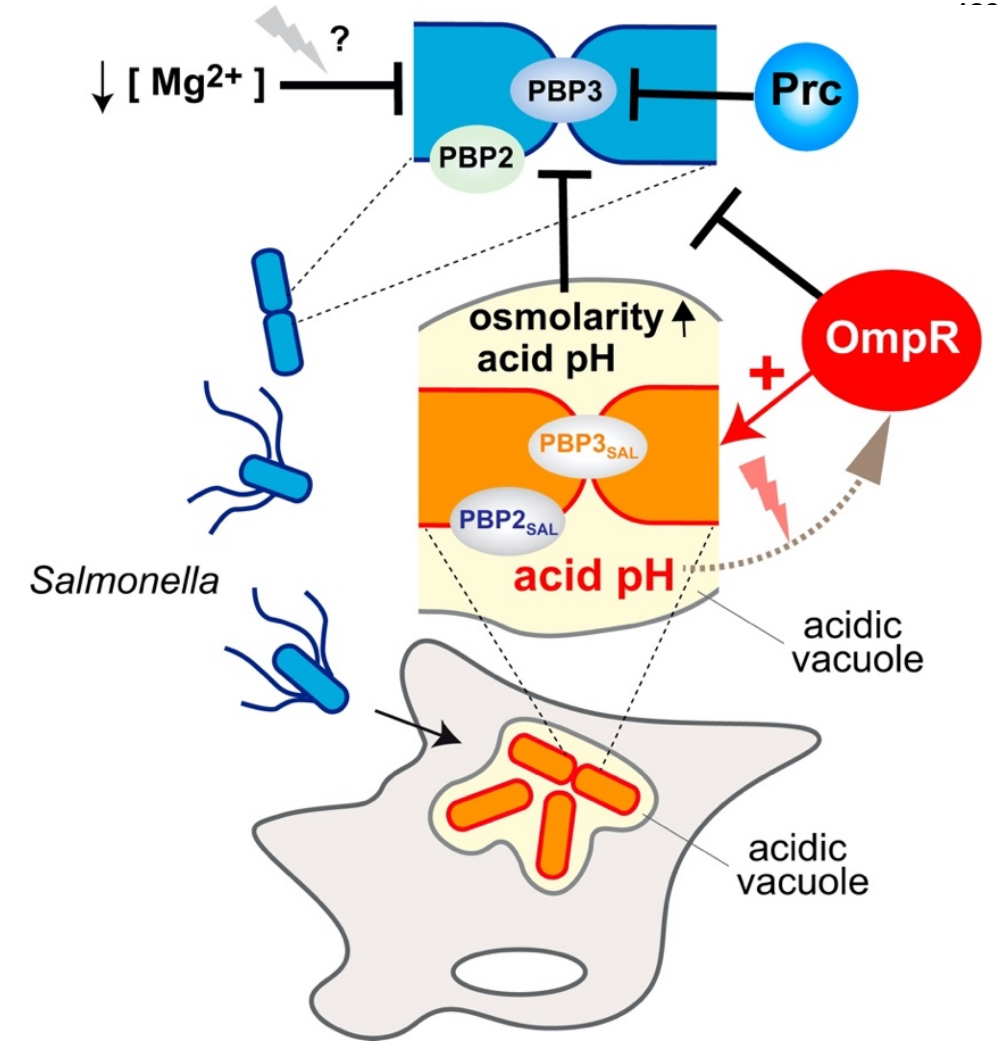

Figure 7. Hypothetical model integrating the regulatory factors that promote in S. Typhimurium the switch of PBP2/PBP3 by $\mathrm{PBP} 2 \mathrm{SAL} / \mathrm{PBP} 3_{\mathrm{SAL}}$ during the transition to the intracellular lifestyle inside acidic vacuoles of the eukaryotic cell. Key regulatory events include the absolute requirement of OmpR for the production of PBP2SAL/PBP3SAL by intracellular bacteria in response to acid $\mathrm{pH}$ and the multifactorial nature that characterizes the negative regulation over PBP2/PBP3 in which $\mathrm{OmpR}$, acid $\mathrm{pH}$, high osmolarity, the protease Prc and a low magnesium concentration may contribute synergistically.

Our study has also shed light into the activity of the protease Prc on PBP3 and PBP3SAL. Our electrophoretic analyses convincingly showed that Prc can cleave both substrates in S. Typhimurium. The significance of the cleavage exerted by the Prc protease in the activity of

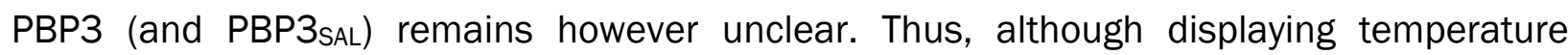
sensitive and outer membrane leaky phenotypes, E. coli mutants lacking Prc are viable [reviewed in (Hara et al., 1996)]. S. Typhimurium prc null mutants are also viable (Hernández 
et al., 2013), indicating that processing of PBP3 and PBP3 ${ }_{S A L}$ is not absolutely essential for

cell division. Nonetheless, the data obtained in S. Typhimurium point to a putative relevant role of Prc in the replacement of the morphogenetic machineries. Unlike its E. coli counterpart, Prc of S. Typhimurium does not cleave PBP3 in acid pH whereas it cleaves this substrate at neutral $\mathrm{pH}$. This behaviour contrasts with its other substrate, PBP3 ${ }_{\mathrm{SAL}}$, which is cleaved at both acid neutral $\mathrm{pH}$ when expressed from plasmid. We also noted that, only for the case of PBP3, the addition of a $6 x \mathrm{His}$ tag in the $\mathrm{N}$-terminus impaired cleavage of this specific enzyme at neutral pH (Fig. 6D), a result that is not easy not be interpreted given the lack of studies addressing the role of the short $\mathrm{N}$-terminal region of the enzyme that faces the cytosol. Tagging this region might therefore has consequences in how PBP3 is recognized by the protease in the periplasm, an effect that may not occur for PBP3 ${ }_{\mathrm{SAL}}$.

An unexpected data was the appearance of small amounts of PBP3 and PBP3SAL in their "nonnatural" conditions, PBP3 SAL $_{\text {in neutral }} \mathrm{pH}$ and PBP3 in acid pH and high osmolarity conditions, when Prc was lacking (Fig. 6E). This result might indicate that Prc exerts a quality control aborting two phenomena: i) the escape that may exist in the negative regulation that OmpR

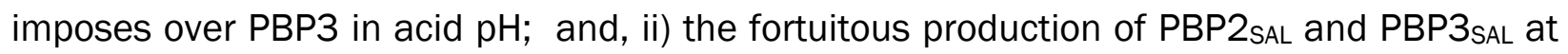
neutral pH dependent on OmpR (Fig. 6E). Whether Prc exerts this role directly on these PG enzymes, is at present unknown.

Our study therefore unravels the first regulatory rules controlling the switch of two morphogenetic machineries involving essential PG synthases that takes place when S. Typhimurium senses acid $\mathrm{pH}$ and high osmolarity. Given that adaptation to these conditions is a requisite for successful infection of eukaryotic cells, it is tempting to speculate that this exchange of PG enzymes might be interconnected to virulence functions activated by S. Typhimurium in response to intra-phagosomal cues. 


\section{Materials and Methods}

Bacterial strains, growth media. Bacterial strains and plasmids used are listed in Table S1.

All S. enterica serovar Typhimurium (S. Typhimurium) strains used are derivates of virulent wild-type strain SV5015, an His + prototroph derivate of virulent strain SL1344 (Vivero et al., 2008). Strains were grown in Luria-Bertani (LB) broth for conditions with high amount of nutrients. LB broth is composed of $1 \%(\mathrm{w} / \mathrm{v})$ casein peptone, $0.5 \%(\mathrm{w} / \mathrm{v})$ yeast extract and $0.5 \%(w / v)$ sodium chloride. For nutrient-limiting conditions simulating the intra-phagosomal environment, strains were grown in phosphate-carbon-nitrogen (PCN) minimal medium (Deiwick and Hensel, 1999) or N minimal medium (Nelson and Kennedy, 1971). The composition of PCN medium is: $4 \mathrm{mM}$ Tricine [N-[Tris (hydroxymethyl) methyl]glycine], $0.1 \mathrm{mM} \mathrm{FeCl}_{3}, 376 \mu \mathrm{M} \mathrm{K}_{2} \mathrm{SO}_{4}, 15 \mathrm{mM} \mathrm{NH}_{4} \mathrm{Cl}, 1 \mathrm{mM} \mathrm{MgSO}_{4}, 10 \mu \mathrm{M} \mathrm{CaCl}_{2}, 0.4 \%$ (w/v) glucose, $0.4 \mathrm{mM} \mathrm{K}_{2} \mathrm{HPO}_{4} / \mathrm{KH}_{2} \mathrm{PO}_{4}$, and micronutrients (Deiwick and Hensel, 1999). $200 \mathrm{mM} \mathrm{NaCl}$ was added to PCN to test response to high osmolarity. $\mathrm{N}$ minimal medium is composed of $5 \mathrm{mM}$

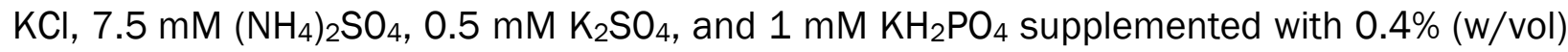
glucose as carbon source, $0.1 \%(\mathrm{w} / \mathrm{vol}$ ) casaminoacids and $10 \mathrm{mM}$ or $8 \mu \mathrm{M} \mathrm{MgCl}$ (high or low $\mathrm{Mg}^{2+}$ concentrations, respectively) (Snavely et al., 1991). When necessary, pH was buffered with $80 \mathrm{mM}$ MES [2-(N-morpholino) ethanesulfonic acid] adjusted to the desired value with $\mathrm{NaOH}$. To grow strains bearing genetic elements conferring antibiotic-resistance, media were supplemented with chloramphenicol $(10 \mu \mathrm{g} / \mathrm{mL})$, kanamycin $(30 \mu \mathrm{g} / \mathrm{mL})$, or ampicillin $(100 \mu \mathrm{g} / \mathrm{mL})$. For induction of gene expression from the Plac promoter in pAC-His plasmids (see Table S1), $10 \mu \mathrm{M}$ IPTG (Isopropyl $\beta$-D-1-thiogalactopyranoside) was added. Plasmids expressing 6xHis-PBP3 and 6xHis-PBP3sal variants tagged in the N-terminus has been previously described (Castanheira et al., 2020). 
Construction of chromosomal epitope-tagged genes. Strains carrying chromosomal 3×FLAGepitope-tagged genes were constructed using the method described by Uzzau et al. (Uzzau et al., 2001). The phage P22 HT 105/1 int201 (Schmieger, 1972) was used for transductional crosses to mobilize mutant alleles for strain construction. The P22 HT transduction protocol was described elsewhere (Garzón et al., 1995). To obtain phage-free isolates, transductants were purified by streaking on green plates, prepared according to Chan et al. (Chan et al., 1972).

\section{Construction of a S. Typhimurium $\Delta$ prc mutant expressing PBP2sAL-3xFLAG and PBP3sAL-}

3xFLAG tagged variants. A P22 HT 105/1 int201 lysate was first obtained from S. Typhimurium strain SV6246 ( $\Delta$ prc::Km²) (Hernández et al., 2013), a gift from J. Casadesús (University of Seville, Spain). This deletion mutant harbors a null allele lacking the entire prc coding sequence (Hernández et al., 2013). The phage lysate was used to transduce strain MD5064 (PBP2sAL-3xFLAG PBP2sAL-3xFLAG) to obtain strain MD5416 (sprc::Km PBP2sAL3xFLAG PBP2SAL-3xFLAG) (Table S1).

Growth conditions for preparation of total protein extracts. When using PCN minimal medium, S. Typhimurium and $\mathrm{E}$. coli strains were first grown overnight with agitation at $37^{\circ} \mathrm{C}, \mathrm{pH} 7.4$ without $\mathrm{NaCl}$ supplementation. To monitor the effect of osmolarity on the production of PBPs, the bacteria from overnight cultures were washed [4,300 x g, $2 \mathrm{~min}$, room temperature (RT)] with PCN medium at the conditions of interest: $\mathrm{pH} 4.6$ or 7.4 , and $\mathrm{NaCl}$ concentrations of $0 \mathrm{mM}$ or $200 \mathrm{mM}$. The initial optical density at $600 \mathrm{~nm}\left(\mathrm{OD}_{600}\right)$ of the culture was established at 0.02 in $20 \mathrm{~mL}$ cultures. When using $\mathrm{N}$ minimal medium, S. Typhimurium strains were grown overnight with agitation at $37^{\circ} \mathrm{C}, \mathrm{pH} 7.4$ with a $\mathrm{MgCl}_{2}$ concentration of $10 \mathrm{mM}$. Overnight cultures were then washed $(4,300 \times g, 2$ min, RT) with $\mathrm{N}$ minimal medium $\mathrm{pH} 4.6$ or 7.4 , and 
$\mathrm{MgCl}_{2}$ concentration of $8 \mu \mathrm{M}$ or $10 \mathrm{mM}$, according to culture growth conditions, and diluted to an initial $\mathrm{OD}_{600}$ of 0.02 in $20 \mathrm{~mL}$ cultures. In minimal media, bacteria were collected after $4 \mathrm{~h}$ of growth at $37^{\circ} \mathrm{C}$ in agitation (150 rpm). When using LB, bacteria were first grown overnight in agitation at $37^{\circ} \mathrm{C}$ in non-buffered neutral pH LB. Overnight cultures were diluted to an initial $\mathrm{OD}_{600}$ of 0.02 in $20 \mathrm{~mL}$ cultures with LB or LB pH 4.6 buffered with MES and bacteria collected at $3 \mathrm{~h}$ post-inoculation. To trigger production of PBP3 or PBP3 $\mathrm{SAL}$ from pACHis plasmids (see Table S1), strains were grown overnight with agitation (150 rpm) at $37^{\circ} \mathrm{C}$ in LB and diluted to an $\mathrm{OD}_{600}$ of 0.02 in fresh LB or LB pH 4.6 buffered with MES. Strains were then grown at $37^{\circ} \mathrm{C}$ for $1.5 \mathrm{~h}$, induced with $10 \mu \mathrm{M}$ IPTG for gene expression and grown for further $1.5 \mathrm{~h}$ before being collected for total protein extraction. In all growth conditions, bacteria were harvested by centrifugation at $18,000 \times \mathrm{g}, 5 \mathrm{~min}, 4^{\circ} \mathrm{C}$, washed twice in phosphate-buffered saline (PBS) and resuspended in $100 \mu \mathrm{L}$ of Laemmli lysis buffer per 591 optical density unit.

Large-scale infection of cultured fibroblasts. Large-scale infections were performed to obtain protein from intracellular bacteria, essentially as previously described (Núñez-Hernández et al., 2013). NRK-49F normal rat kidney fibroblasts (ATCC CRL-1570) were seeded in Nunc Square BioAssay Dishes (Thermo Scientific, ref. 166508) with 50 mL Dulbecco's Modified Eagle Medium (DMEM) culture medium supplemented with $5 \%(\mathrm{v} / \mathrm{v})$ foetal bovine serum (FBS) and $4 \mathrm{mM} \mathrm{L-glutamine} \mathrm{to} \mathrm{a} \mathrm{confluence} \mathrm{of} 80 \%\left(\sim 5.0 \times 10^{7}\right.$ cells $)$. The fibroblast culture was infected with the different S. Typhimurium strains, previously grown overnight at $37^{\circ} \mathrm{C}$ in static LB culture, for 40 min at an MOI of 10:1 (bacteria: fibroblast). At this time post-infection, cells were washed two times with prewarmed complete PBS solution (PBS pH 7.4 with 0.9 $\mathrm{mM} \mathrm{CaCl} 20.5 \mathrm{mM} \mathrm{MgCl}_{2}$ ) and then incubated in fresh DMEM-5\% FBS culture medium containing $100 \mu \mathrm{g} / \mathrm{mL}$ of gentamicin until $2 \mathrm{~h}$ post-infection. The culture medium was then 
replaced with fresh DMEM-5\% FBS medium containing $10 \mu \mathrm{g} / \mathrm{mL}$ gentamicin until $8 \mathrm{~h}$ post-infection. At that time, the infected fibroblasts were washed five times with $20 \mathrm{~mL}$ cold complete PBS and lysed in $17 \mathrm{~mL}$ of a solution containing $1 \%(\mathrm{v} / \mathrm{v}) \mathrm{pH}$ 6.6-7.9 basic phenol, $19 \%(\mathrm{v} / \mathrm{v})$ ethanol and 0,4 \% (w/v) SDS in water. A volume of $1.2 \mu \mathrm{L}$ DNase $(10 \mathrm{mg} / \mathrm{mL})$ was added to each plate. After 30 min of incubation at $4^{\circ} \mathrm{C}$, the lysate was collected in $40 \mathrm{~mL}$ polypropylene tubes (Sorvall) and centrifuged $\left(27,500 \times g, 4^{\circ} \mathrm{C}, 30 \mathrm{~min}\right)$. The resultant pellet was washed twice with $1 \mathrm{~mL}$ of a $1 \%$ basic phenol, $19 \%$ ethanol solution $(29400 \times \mathrm{g}, 15 \mathrm{~min}$, $\left.4^{\circ} \mathrm{C}\right)$. Intracellular bacteria were resuspended in $40 \mu \mathrm{L}$ Laemmli lysis buffer.

Immunoblot assays. For SDS/PAGE, samples were incubated at $100^{\circ} \mathrm{C}$ for $5-10 \mathrm{~min}$ and centrifuged to remove cell debris $(6,800 \times$ g, $5 \mathrm{~min}, \mathrm{RT})$ for SDS/PAGE. Proteins resolved by gels were transferred to polyvinylidene difluoride (PVDF) membranes and incubated with the corresponding antibodies. Detection was performed by Clarity Western ECL Substrate chemioluminescence kit (Bio Rad, ref. 1705061). Once used for the Western blot, the PVDF membranes were stained with Coomassie solution to confirm proper adjustment of samples except samples from intracellular bacteria, in which immunodetection of DnaK chaperone was made. Proteins were routinely resolved in $6 \%$ polyacrylamide gels. To increase the separation of mature and processed PBP3 forms, 11\% gels for the Tricine-electrophoresis system (Schägger and von Jagow, 1987), were used. Similarly, to increase separation 621 between PBP2sAL and PBP3 saL, 4-20\% Mini-PROTEAN TGX Precast Protein gels (BioRad, ref. 4561096), were used. The following antibodies were used as primary antibodies: mouse monoclonal anti-Flag (M2 clone, 1:5000; Sigma), mouse monoclonal anti-6xHis (1:2500; R\&D Systems), rabbit polyclonal anti-PBP2 (1:1000; lab collection) (Castanheira et al., 2020), rabbit polyclonal anti-PBP3 (1:1000; lab collection) (Castanheira et al., 2017) and, mouse monoclonal anti-DnaK (clone 8E2/2, 1:10000; Enzo Life Sciences). Goat polyclonal anti- 
mouse (ref. 1706516, 1:20000, BioRad) and anti-rabbit IgG (ref. 1706515, 1:30000, BioRad) conjugated to horseradish peroxidase (Bio-Rad), were used as secondary antibodies.

Phase-contrast microscopy. Bacteria in overnight cultures were centrifuged $(4,300 \times \mathrm{g}, 2 \mathrm{~min}$, $\mathrm{RT}$ ), washed in PCN medium with the corresponding $\mathrm{pH}$ (4.6 or 7.4) and salt concentration ( $0 \mathrm{mM}$ or $200 \mathrm{mM} \mathrm{NaCl}$ ) and used to inoculate the respective media to an initial optical $\mathrm{OD}_{600}$ of 0.02 . After $4 \mathrm{~h}$ growing with agitation $(150 \mathrm{rpm})$ at $37^{\circ} \mathrm{C}$, bacteria were harvested $(6,800 \times$ g, $4 \mathrm{~min}, 4^{\circ} \mathrm{C}$ ), washed twice in PBS buffer, fixed with 3\% paraformaldehyde (PFA) for $10 \mathrm{~min}$ and adjusted to a final paraformaldehyde (PFA) concentration of $1 \%$. For microscopy, fixed bacteria were centrifuged (4,300 × g, $4 \mathrm{~min}, \mathrm{RT})$ and resuspended in an equal volume of PBS. A volume of $30 \mu \mathrm{L}$ was dropped on poly-L-Lys pretreated coverslips and incubated for $10 \mathrm{~min}$ at RT. Attached bacteria were washed four times with PBS and the coverslip mounted on slides using ProLong Gold Antifade (Molecular Probes). Images were acquired on an inverted Leica DMI 6000B microscope with an automated CTR/7000 HS controller (Leica Microsystems) and an Orca-R2 charge-coupled-device (CCD) camera (Hamamatsu Photonics).

\section{Construction of reporter plasmids involving PBP2 ${ }_{S A L}$ and PBP3 $3_{S A L}$ promoter regions. To} a vector with the backbone of plasmid pGEN222 (Galen et al., 1999) bearing an ovoalbumin (OVA)-encoding gene under the PompC promoter and a gene expressing GFPTCD variant (Corcoran et al., 2010), was used. This vector, kindly provided by L.A. Fernández (CNB-CSIC, Madrid, Spain), is named pGEN222-ova-gfp. Regions encompassing 250 pb upstream the start codon of PBP2SAL- and PBP3sAL-encoding genes (SL1344_1845 and SL1344_1765, respectively) were amplified from S. Typhimurium SV5015 genomic DNA (gDNA) using the primers Ppbp2sal_EcoRI_Notl_Fw/Ppbp2sal_EcoRI_Notl_Rv and Ppbp3sal_EcoRI_Notl_Fw/ Ppbp3sal_EcoRI_Notl_Rv (Table S2). The PCR products containing the PBP2 ${ }_{\text {SAL }}$ and PBP3 $\mathrm{SAL}$ 
promoter regions were digested with EcoRI and Notl and ligated in an EcoRI/Notl-digested pGEN222-ova-gfp replacing, as a result, the pompC-ova region. As negative control, this pompC-ova region was excised with EcoRI/Notl from pGEN222-ova-gfp and the plasmid was religated. To this aim, pGEN222-ova-gfp digested with EcoRI and Notl was incubated with T4 DNA polymerase (Roche) for $15 \mathrm{~min}$ at $12^{\circ} \mathrm{C}$, then $2.5 \mu \mathrm{L}$ of EDTA-Na+ $0.1 \mathrm{M}$ were added. The mixture was re-incubated $20 \mathrm{~min}$ at $75^{\circ} \mathrm{C}$ and the purified DNA product further incubated overnight at $16^{\circ} \mathrm{C}$ with a T4 DNA ligase (Roche).

\section{Construction of mutated versions of the OmpR boxes in the PBP2sAL and PBP3saL promoters.}

An annealing extension procedure was used for generating PBP2 ${ }_{\text {SAL }}$ and PBP3 ${ }_{S A L}$ promoters with altered OmpR boxes. These regions were amplified in two fragments from plasmids

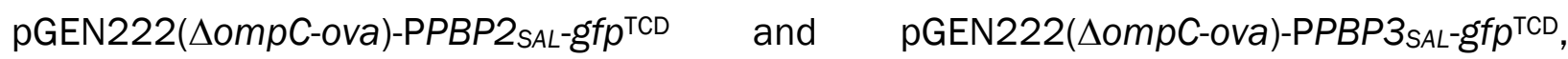
respectively. Fragments with mutations at putative OmpR-binding sites were amplified using 663 the following primers: (i) pPBP2sal_mut_Fw/pPBP2sal_EcoRI_Notl_Rv and pPBP2sal_mut_Rv/ pPBP2sal_EcoRI_Notl_Fw for the PBP2sAL promoter; and, (ii) pPBP3sal_mut_Fw/ pPBP3sal_EcoRI_Notl_Rv and pPBP3sal_mut_Rv/

666 pPBP3sal_EcoRI_Notl_Fw, for the PBP3 SAL promoter (Table S2). Then, the fragments for each construction were co-incubated for 5 cycles of annealing extension and the resulting fulllength fragment were amplified using external primers Ppbp2sal_EcoRI_Notl_Fw/ Ppbp2sal_EcoRI_Notl_Rv and Ppbp3sal_EcoRI_Notl_Fw/ Ppbp3sal_EcoRI_NotI_Rv for 30 cycles. The resulting fragments were digested with EcoRI and Notl restriction enzymes, purified and ligated in a EcoRI-Notl digested pGEN222-derivative vector. All constructs were sequenced with primer pGEN222_Fw (Table S2) to rule out the presence of undesired mutations. The reporter plasmids vectors harboring the mutated versions of the PBP2SAL and PBP3 saL promoters were electroporated into the desired S. Typhimurium and E. coli strains. 
Monitoring of promoter activity with reporter plasmids expressing GFPTCD. The S. Typhimurium and E. coli strains harboring the reporter plasmids with the PBP2 ${ }_{S A L}$ and PBP3SAL promoter regions were grown overnight in $\mathrm{PCN}$ minimal medium $\mathrm{pH} 7.4,200 \mathrm{mM} \mathrm{NaCl}$ at or 7.4 and, finally resuspended in these respective media at an initial $\mathrm{OD}_{600}$ of 0.02 . These cultures were transferred with volumes of $180 \mu \mathrm{L}$ per well in triplicate into 96-well flat clear bottom black polystyrene TC-treated microplates (Corning®, ref. 3904). Bacteria were incubated at $37^{\circ} \mathrm{C}$ for $18 \mathrm{~h}$ with $20 \mathrm{sec}$ of orbital agitation every $20 \mathrm{~min}$, followed by $\mathrm{OD}_{600}$ and fluorescence measurements in a Spark $^{\circledR}$ microplate multimode reader (TECAN). 684 Fluorescence units (FU) were measured with wavelength excitation at 475/15 $\mathrm{nm}$ and emission at 510/15 $\mathrm{nm}$. The background values of both optical density and fluorescence were subtracted in the values of the bacterial samples. Fluorescence units were finally corrected by optical density for graphical representation.

DNA techniques. All primers used in this study are listed in Table S2. PCR was performed using Q5 polymerase (New England Biolabs) according to manufacture instructions. PCR 690 fragments were purified using the NucleoSpin Gel and PCR Clean-up kit (Macherey-Nagel, ref. 740609.50). Plasmids were purified using the NZYMiniprep kit (NZYTech, ref. MB01001).

Measurements and statistical analysis. Intensity of protein bands obtained in the immunoassays was measured with Fiji distribution of ImageJ2 (version 1.52i) (Schindelin et al., 2012). Similar band expositions for reference strain were selected to increase the comparability between data of distinct biological replicates. Data were analyzed with GraphPad Prism software v8.0 (GraphPad Inc. San Diego, CA) using unpaired two-tailed Student's $t$ test. Significance was established at P-values $<0.05$. 


\section{Acknowledgements}

We thank J. Casadesús (University of Seville, Spain) and M. Hensel (University of Osnabrück, Germany) for the gift of S. Typhimurium strains and, L.A. Fernández (CNB-CSIC, Madrid, Spain) for the expression vector derivate of vector pGEN222 used for the construction of the reporter plasmids. We also thank Gadea Rico-Peréz for the construction of some tagged S. Typhimurium strains and Henar González for the technical support. D.L.-E. is supported by a PhD fellowship from the "Programa de Formación de Personal Investigador (FPI)" of the Spanish Ministry of Science and Innovation (ref. BES-2017-080709). This work was supported by grant PID2020-112971GB-I00 from the Spanish Ministry of Science and Innovation to F.G-dP. 
Table S1. Bacterial strains and plasmids used in the study

\begin{tabular}{|c|c|c|}
\hline $\begin{array}{l}\text { Bacterial strain/ } \\
\text { plasmid }\end{array}$ & Relevant genotype & $\begin{array}{l}\text { Source/ } \\
\text { reference }\end{array}$ \\
\hline \multicolumn{3}{|l|}{ S. Typhimurium } \\
\hline SV5015 & SL1344, hisG $^{+}$ & $\begin{array}{c}\text { (Vivero et al., } \\
2008 \text { ) }\end{array}$ \\
\hline MD5064 & SV5015 PBP2sAL-3xFLAG PBP3SAL-3xFLAG & $\begin{array}{l}\text { (Castanheira } \\
\text { et al., 2020) }\end{array}$ \\
\hline MD5080 & SV5015 ompR1009::Tn10 PBP2sAL-3xFLAG PBP3sAL-3xFLAG & This study \\
\hline MD5540 & SV5015 phoP7953::Tn10 PBP2sAL-3xFLAG PBP3sAL-3xFLAG & This study \\
\hline MD2540 & SV5015 PBP2SAL-3xFLAG::KmR & This study \\
\hline MD3841 & SV5015 ompR1009::Tn10 PBP2sAL-3xFLAG & This study \\
\hline MD3896 & SV5015 phoP7953::Tn10 PBP2sAL-3xFLAG & This study \\
\hline MD3894 & SV5015 slyA::pRR10 & This study \\
\hline MD5140 & SV5015 ssrB:: KmR PBP2sAL-3xFLAG & M. Hensel \\
\hline MD2559 & SV5015 PBP3sAL-3xFLAG & $\begin{array}{l}\text { (Castanheira } \\
\text { et al., 2017) }\end{array}$ \\
\hline MD3842 & SV5015 ompR1009::Tn10 PBP3sAL-3xFLAG & $\begin{array}{l}\text { (Castanheira } \\
\text { et al., 2017) }\end{array}$ \\
\hline MD3897 & SV5015 phoP7953::Tn10 PBP3sAL-3xFLAG & $\begin{array}{l}\text { (Castanheira } \\
\text { et al., 2017) }\end{array}$ \\
\hline MD3895 & SV5015 slyA::pRR10 & $\begin{array}{l}\text { (Castanheira } \\
\text { et al., 2017) }\end{array}$ \\
\hline MD5139 & SV5015 ssrB:: KmR PBP3sAL-3xFLAG & M. Hensel \\
\hline MD5416 & SV5015 $\Delta$ prc::KmR PBP2sAL-3xFLAG PBP3sAL-3xFLAG & This study \\
\hline MD5420 & $\begin{array}{l}\text { SV5015 ompR1009::Tn10 } \Delta p r c:: K m^{R} \text { PBP2sAL-3xFLAG } \\
\text { PBP3sAL-3xFLAG }\end{array}$ & This study \\
\hline MD5421 & SV5015 mrcA-3xFLAG::KmR PBP2sAL-3xFLAG PBP3sAL-3xFLAG & This study \\
\hline MD5422 & SV5015 mrcB-3xFLAG::KmR PBP2sAL-3xFLAG PBP3sAL-3xFLAG & This study \\
\hline MD5425 & SV5015 pAC-6xHis-ftsI (6xHis-PBP3) & This study \\
\hline MD5426 & SV5015 $\Delta p r c:: K m^{R}$ pAC-6xHis-ftsI (6xHis-PBP3) & This study \\
\hline MD5427 & SV5015 pAC-6xHis-PBP3SAL & This study \\
\hline MD5428 & SV5015 $\Delta p r c:: K^{R}$ pAC-6xHis-PBP3sAL & This study \\
\hline MD5436 & SV5015 pGEN222( $\triangle$ PompC-ova)-PPBP2sAL- gfp ${ }^{\text {тc }}$ & This study \\
\hline MD5437 & SV5015 pGEN222( $($ PompC-ova)-PPBP3saL- gfpтсо & This study \\
\hline MD5438 & $\begin{array}{l}\text { SV5015 ompR1009::Tn10 pGEN222(APompC-ova)-PPBP2sAL- } \\
\text { gfpтс }\end{array}$ & This study \\
\hline
\end{tabular}


MD5439

MD5440

MD5441

MD5446

MD5447

MD5449

MD5451

MD5077

MD3238

MD3843

E. coli

SV5015 ompR1009::Tn10 pGEN222(APompC-ova)-PPBP3SAL-

This study gfp ${ }^{\mathrm{TCD}}$

SV5015 phoP7953::Tn10 pGEN222(APompC-ova)-PPBP2SAL-

This study gfp

SV5015 phoP7953::Tn10 pGEN222(APompC-ova)-PPBP3SALgfртс

This study

SV5015 pGEN222( $\triangle$ PompC-ova)-mut-PPBP2sAL

This study (TGTAACAA>GCTCGGAC)- gfp

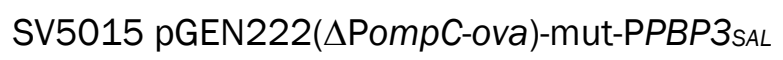

This study (TGTTGCAA>GCTCGGAC)- gfp тсD

SV5015 pGEN222( $\triangle$ PompC-ova) (promoter-less vector)

This study

SV5015 rpoS::CmR PBP2sAL-3xFLAG PBP3SAL-3xFLAG

This study

SV5015 rpoE::KmR PBP2sAL-3xFLAG PBP3SAL-3xFLAG

This study

SV5015 dacC-3xFLAG::KmR

This study

SV5015 ompR1009::Tn10 dacC-3xFLAG::Km

This study

\begin{tabular}{|c|c|c|}
\hline MG1655 & $\mathrm{K}-12$, wild type & \\
\hline MD5442 & MG1655 pGEN222(APompC-ova)::P-PBP2sAL-gfp & This study \\
\hline MD5443 & 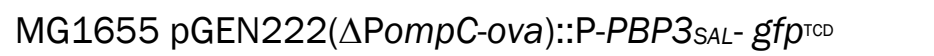 & This study \\
\hline MD5450 & MG1655 pGEN222(APompC-ova) (promoter-less vector) & This study \\
\hline \multicolumn{3}{|l|}{ Plasmids } \\
\hline pAC-6xHIS-Plac & $\mathrm{Cm}^{\mathrm{R}}$ & $\begin{array}{l}\text { (Castanheira } \\
\text { et al., 2017) }\end{array}$ \\
\hline pCP20 & $\mathrm{FLP}+, \mathrm{Amp}^{\mathrm{R}}, \mathrm{Cm}^{\mathrm{R}}$ & $\begin{array}{c}\text { (Cherepanov } \\
\text { and } \\
\text { Wackernagel, } \\
\text { 1995) }\end{array}$ \\
\hline pSUB11 & 3xFLAG sequence, $\mathrm{Km}^{\mathrm{R}}$ & $\begin{array}{c}\text { (Uzzau et al., } \\
2001)\end{array}$ \\
\hline pKD46 & $\mathrm{Y}, \beta$, exo. Amp ${ }^{\mathrm{R}}$ & $\begin{array}{c}\text { (Datsenko and } \\
\text { Wanner, } \\
\text { 2000) }\end{array}$ \\
\hline pGEN222 & AmpR; p15A-ori, hok/sok stability system, PompC::gfp-UV & $\begin{array}{c}\text { (Galen et al., } \\
\text { 1999) }\end{array}$ \\
\hline pGEN222-ova-gfp & pGEN222-PompC-ova-gfpтср & $\begin{array}{l}\text { L.A. } \\
\text { Fernández }\end{array}$ \\
\hline
\end{tabular}


Table S2. Oligonucleotides used in this study as primers

\begin{tabular}{|c|c|}
\hline Primer name & Sequence $\left(5^{\prime}-3^{\prime}\right){ }^{(*)}$ \\
\hline FLAG MrcA Fw & АCCATTATTGATAATGGTGAAACACACGAACTGTTCGACTACAAAGACCATGACGG \\
\hline FLAG MrcA Rv & GCTAAACACAATAAAAAAGGCGCCGGAGCGCCTTTTTTGACATATGAATATCCTCCTTAG \\
\hline FLAG MrcB Fw & GTTGCCGGCTGGATTAAGGAGATGTTCGGCGGCAATGACTACAAAGACCATGACGG \\
\hline FLAG MrcB Rv & GACCGGGTAAGCACAGCGCCACCCGGCACTATTACCGTGACATATGAATATCCTCCTTAG \\
\hline FLAG PBP 2* Fw & TGATCCACAGGCTGATACCACACAGCCGGATCAGGCGCCAGACTACAAAGACCATGACGG \\
\hline FLAG PBP $2 *$ Rv & TCCGGCCGTATCCTTGTCTGATGGCGCTTTGCTTATTTGACATATGAATATCCTCCTTAG \\
\hline FLAG PBP $3 *$ FW & TCTGGTGATGCATGGCAGCCACGTTGCGGTTCCGGGTTCGGACTACAAAGACCATGACGG \\
\hline FLAG PBP 3* Rv & GGGCGCAAGTGTAACGCGAATTGCGCCCCGGGAAAATCCTCATATGAATATCCTCCTTAG \\
\hline pPBP2sal_EcoRI_Notl_Fw & GCGAATTCGGCGCAACTGACGGCGAAG \\
\hline pPBP2sal_EcoRI_Notl_Rv & ATAAGAATGCGGCCGCGAACAATCCGCCGCCTAATG \\
\hline pPBP3sal_EcoRI_Notl_Fw & GCGAATTCCCAGAAAGGTCCGGCTG \\
\hline pPBP3sal_EcoRI_Notl_Rv & ATAAGAATGCGGCCGCAGCCGAATCATTTTTCAGG \\
\hline pPBP2sal_mut_Fw & GCCACAGCGGTATATCGCTCGGACATCACAAGGAATGAC \\
\hline pPBP2sal_mut_Rv & GTCATTCCTTGTGATGTCCGAGCGATATACCGCTGTGGC \\
\hline pPBP3sal_mut_Fw & GCTCTCGTTAGCGATTGCTCGGACAGGCGCGATGTTATTAG \\
\hline pPBP3sal_mut_Rv & СТАATAACATCGCGCCTGTCCGAGCAATCGCTAACGAGAGC \\
\hline pGEN222_Fw & GTCTCTGTTATTCAGGCAATTTC \\
\hline FLAG PBP6 FW & GCTGATGAAACTCCATCAGTGGTTTGGCAGTTGGTTCTCGGACTACAAAGACCATGACGG \\
\hline FLAG PBP6 Rv & CCGTAGCCGGATGCGACGCGCACCCGGCTACGGAGTTATTCATATGAATATCCTCCTTAG \\
\hline
\end{tabular}

(*) Bold red: restriction enzyme sites; underlined: sequences of the mutated OmpR box variants; blue colour, sequence of pSUB11 vector. 


\section{References}

Adams PP, Baniulyte G, Esnault C, Chegireddy K, Singh N, Monge M, Dale RK, Storz G, Wade JT. 2021. Regulatory roles of Escherichia coli 5' UTR and ORF-internal RNAs detected by 3' end mapping. Elife 10:e62438. doi:10.7554/eLife.62438

Alphen WV, Lugtenberg B. 1977. Influence of osmolarity of the growth medium on the outer membrane protein pattern of Escherichia coli. J Bacteriol 131:623-630. doi:10.1128/jb.131.2.623-630.1977

Banda MM, Zavala-Alvarado C, Pérez-Morales D, Bustamante VH. 2019. SlyA and HilD Counteract H-NSMediated Repression on the ssrAB Virulence Operon of Salmonella enterica Serovar Typhimurium and Thus Promote Its Activation by OmpR. J Bacteriol 201:e00530-18. doi:10.1128/JB.00530-18

Brosse A, Korobeinikova A, Gottesman S, Guillier M. 2016. Unexpected properties of sRNA promoters allow feedback control via regulation of a two-component system. Nucleic Acids Res 44:9650-9666. doi:10.1093/nar/gkw642

Buchmeier N, Bossie S, Chen CY, Fang FC, Guiney DG, Libby SJ. 1997. SlyA, a transcriptional regulator of Salmonella typhimurium, is required for resistance to oxidative stress and is expressed in the intracellular environment of macrophages. Infect Immun 65:3725-3730. doi:10.1128/iai.65.9.3725-3730.1997

Caccamo PD, Brun YV. 2018. The Molecular Basis of Noncanonical Bacterial Morphology. Trends Microbiol 26:191-208. doi:10.1016/j.tim.2017.09.012

Cameron ADS, Dorman CJ. 2012. A fundamental regulatory mechanism operating through OmpR and DNA topology controls expression of Salmonella pathogenicity islands SPI-1 and SPI-2. PLoS Genet 8:e1002615. doi:10.1371/journal.pgen.1002615

Cano DA, Martínez-Moya M, Pucciarelli MG, Groisman EA, Casadesús J, García-Del Portillo F. 2001. Salmonella enterica serovar Typhimurium response involved in attenuation of pathogen intracellular proliferation. Infect Immun 69:6463-6474. doi:10.1128/IAI.69.10.6463-6474.2001

Castanheira S, Cestero JJ, Rico-Pérez G, García P, Cava F, Ayala JA, Pucciarelli MG, García-Del Portillo F. 2017. A Specialized Peptidoglycan Synthase Promotes Salmonella Cell Division inside Host Cells. mBio 8:e01685-17. doi:10.1128/mBio.01685-17

Castanheira S, Lopez-Escarpa D, Pucciarelli MG, Cestero JJ, Baquero F, Garcia-Del Portillo F. 2020. An alternative penicillin-binding protein involved in Salmonella relapses following ceftriaxone therapy. EBioMedicine 55:102771. doi:10.1016/j.ebiom.2020.102771

Chakraborty S, Kenney L. 2018. A New Role of OmpR in Acid and Osmotic Stress in Salmonella and E. coli. Front Microbiol 9:2656. doi:10.3389/fmicb.2018.02656

Chan RK, Botstein D, Watanabe T, Ogata Y. 1972. Specialized transduction of tetracycline resistance by phage P22 in Salmonella typhimurium. II. Properties of a high-frequency-transducing lysate. Virology 50:883-898. doi:10.1016/0042-6822(72)90442-4

Chen CY, Eckmann L, Libby SJ, Fang FC, Okamoto S, Kagnoff MF, Fierer J, Guiney DG. 1996. Expression of Salmonella typhimurium rpoS and rpoS-dependent genes in the intracellular environment of eukaryotic cells. Infect Immun 64:4739-4743. doi:10.1128/iai.64.11.4739-4743.1996

Chen HD, Groisman EA. 2013. The biology of the PmrA/PmrB two-component system: the major regulator of lipopolysaccharide modifications. Annu Rev Microbiol 67:83-112. doi:10.1146/annurev-micro092412-155751

Cherepanov PP, Wackernagel W. 1995. Gene disruption in Escherichia coli: TcR and KmR cassettes with the option of Flp-catalyzed excision of the antibiotic-resistance determinant. Gene 158:9-14. doi:10.1016/0378-1119(95)00193-a

Cho H. 2015. The role of cytoskeletal elements in shaping bacterial cells. J Microbiol Biotechnol 25:307316. doi:10.4014/jmb.1409.09047

Choi J, Groisman EA. 2016. Acidic pH sensing in the bacterial cytoplasm is required for Salmonella virulence. Mol Microbiol 101:1024-1038. doi:10.1111/mmi.13439

Corcoran CP, Cameron ADS, Dorman CJ. 2010. H-NS silences gfp, the green fluorescent protein gene: gfpTCD is a genetically Remastered gfp gene with reduced susceptibility to H-NS-mediated transcription silencing and with enhanced translation. J Bacteriol 192:4790-4793. doi:10.1128/JB.00531-10 
Daitch AK, Goley ED. 2020. Uncovering Unappreciated Activities and Niche Functions of Bacterial Cell Wall Enzymes. Curr Biol 30:R1170-R1175. doi:10.1016/j.cub.2020.07.004

Dalebroux ZD, Miller SI. 2014. Salmonellae PhoPQ regulation of the outer membrane to resist innate immunity. Curr Opin Microbiol 17:106-113. doi:10.1016/j.mib.2013.12.005

Datsenko KA, Wanner BL. 2000. One-step inactivation of chromosomal genes in Escherichia coli K-12 using PCR products. Proc Natl Acad Sci U S A 97:6640-6645. doi:10.1073/pnas.120163297

Deiwick J, Hensel M. 1999. Regulation of virulence genes by environmental signals in Salmonella typhimurium. Electrophoresis 20:813-7. doi:10.1002/(SICl)1522-2683(19990101)20:4/5

den Blaauwen T, de Pedro MA, Nguyen-Disteche M, Ayala JA. 2008. Morphogenesis of rod-shaped sacculi. FEMS Microbiol Rev 32:321-44. doi:10.1111/j.1574-6976.2007.00090.x

den Blaauwen T, Hamoen LW, Levin PA. 2017. The divisome at 25: the road ahead. Curr Opin Microbiol 36:85-94. doi:10.1016/j.mib.2017.01.007

den Blaauwen T, Luirink J. 2019. Checks and Balances in Bacterial Cell Division. mBio 10. doi:10.1128/mBio.00149-19

Egan AJ, Cleverley RM, Peters K, Lewis RJ, Vollmer W. 2017. Regulation of bacterial cell wall growth. FEBS J 284:851-867. doi:10.1111/febs.13959

Egan AJ, Vollmer W. 2013. The physiology of bacterial cell division. Ann N Y Acad Sci 1277:8-28. doi:10.1111/j.1749-6632.2012.06818.x

Egan AJF, Errington J, Vollmer W. 2020. Regulation of peptidoglycan synthesis and remodelling. Nature Reviews Microbiology 18:446-460. doi:10.1038/s41579-020-0366-3

Eriksson S, Lucchini S, Thompson A, Rhen M, Hinton JC. 2003. Unravelling the biology of macrophage infection by gene expression profiling of intracellular Salmonella enterica. Mol Microbiol 47:103-18.

Errington J. 2015. Bacterial morphogenesis and the enigmatic MreB helix. Nat Rev Microbiol 13:241-8. doi:10.1038/nrmicro3398

Fass E, Groisman EA. 2009. Control of Salmonella pathogenicity island-2 gene expression. Curr Opin Microbiol 12:199-204. doi:10.1016/j.mib.2009.01.004

Feng X, Oropeza R, Kenney $\sqcup$. 2003. Dual regulation by phospho-OmpR of ssrA/B gene expression in Salmonella pathogenicity island 2. Mol Microbiol 48:1131-1143. doi:10.1046/j.13652958.2003.03502.x

Galen JE, Nair J, Wang JY, Wasserman SS, Tanner MK, Sztein MB, Levine MM. 1999. Optimization of plasmid maintenance in the attenuated live vector vaccine strain Salmonella typhi CVD 908-htrA. Infect Immun 67:6424-6433. doi:10.1128/IAl.67.12.6424-6433.1999

García Véscovi E, Soncini FC, Groisman EA. 1996. Mg2+ as an extracellular signal: environmental regulation of Salmonella virulence. Cell 84:165-174. doi:10.1016/s0092-8674(00)81003-x

García-del Portillo F, Núñez-Hernández C, Eisman B, Ramos-Vivas J. 2008. Growth control in the Salmonella-containing vacuole. Curr Opin Microbiol 11:46-52. doi:10.1016/j.mib.2008.01.001

Garmendia J, Beuzón CR, Ruiz-Albert J, Holden DW. 2003. The roles of SsrA-SsrB and OmpR-EnvZ in the regulation of genes encoding the Salmonella typhimurium SPI-2 type III secretion system. Microbiology (Reading) 149:2385-2396. doi:10.1099/mic.0.26397-0

Garzón A, Cano DA, Casadesús J. 1995. Role of Erf recombinase in P22-mediated plasmid transduction. Genetics 140:427-434. doi:10.1093/genetics/140.2.427

Hara H, Abe N, Nakakouji M, Nishimura Y, Horiuchi K. 1996. Overproduction of penicillin-binding protein 7 suppresses thermosensitive growth defect at low osmolarity due to an spr mutation of Escherichia coli. Microb Drug Resist 2:63-72. doi:10.1089/mdr.1996.2.63

Hara H, Nishimura Y, Kato J, Suzuki H, Nagasawa H, Suzuki A, Hirota Y. 1989. Genetic analyses of processing involving C-terminal cleavage in penicillin-binding protein 3 of Escherichia coli. J Bacteriol 171:5882-5889. doi:10.1128/jb.171.11.5882-5889.1989

Hautefort I, Thompson A, Eriksson-Ygberg S, Parker ML, Lucchini S, Danino V, Bongaerts RJ, Ahmad N, Rhen M, Hinton JC. 2008. During infection of epithelial cells Salmonella enterica serovar Typhimurium undergoes a time-dependent transcriptional adaptation that results in simultaneous expression of three type 3 secretion systems. Cell Microbiol 10:958-84. doi:CMI1099 [pii] 10.1111/j.14625822.2007.01099.x 
Hernández SB, Ayala JA, Rico-Pérez G, García-del Portillo F, Casadesús J. 2013. Increased bile resistance in Salmonella enterica mutants lacking Prc periplasmic protease. Int Microbiol 16:87-92. doi:10.2436/20.1501.01.183

Horvath DJ, Li B, Casper T, Partida-Sanchez S, Hunstad DA, Hultgren SJ, Justice SS. 2011. Morphological plasticity promotes resistance to phagocyte killing of uropathogenic Escherichia coli. Microbes Infect 13:426-437. doi:10.1016/j.micinf.2010.12.004

Hsu P-C, Chen C-S, Wang S, Hashimoto M, Huang W-C, Teng C-H. 2020. Identification of MItG as a PrC Protease Substrate Whose Dysregulation Contributes to the Conditional Growth Defect of Prc-Deficient Escherichia coli. Front Microbiol 11:2000. doi:10.3389/fmicb.2020.02000

Justice SS, Hunstad DA, Cegelski L, Hultgren SJ. 2008. Morphological plasticity as a bacterial survival strategy. Nat Rev Microbiol 6:162-168. doi:10.1038/nrmicro1820

Justice SS, Hunstad DA, Seed PC, Hultgren SJ. 2006. Filamentation by Escherichia coli subverts innate defenses during urinary tract infection. Proc Natl Acad Sci U S A 103:19884-19889. doi:10.1073/pnas.0606329104

Kenney L. 2019. The role of acid stress in Salmonella pathogenesis. Curr Opin Microbiol 47:45-51. doi:10.1016/j.mib.2018.11.006

Khanna K, Lopez-Garrido J, Pogliano K. 2020. Shaping an Endospore: Architectural Transformations During Bacillus subtilis Sporulation. Annu Rev Microbiol 74:361-386. doi:10.1146/annurev-micro022520-074650

Kim CC, Falkow S. 2004. Delineation of upstream signaling events in the salmonella pathogenicity island 2 transcriptional activation pathway. J Bacteriol 186:4694-4704. doi:10.1128/JB.186.14.46944704.2004

Kroger C, Colgan A, Srikumar S, Handler K, Sivasankaran SK, Hammarlof DL, Canals R, Grissom JE, Conway T, Hokamp K, Hinton JC. 2013. An infection-relevant transcriptomic compendium for Salmonella enterica Serovar Typhimurium. Cell Host Microbe 14:683-95. doi:10.1016/j.chom.2013.11.010

Kunkle DE, Bina XR, Bina JE. 2020. Vibrio cholerae OmpR Contributes to Virulence Repression and Fitness at Alkaline pH. Infect Immun 88:e00141-20. doi:10.1128/IAI.00141-20

Lee AK, Detweiler CS, Falkow S. 2000. OmpR regulates the two-component system SsrA-ssrB in Salmonella pathogenicity island 2. J Bacteriol 182:771-781. doi:10.1128/JB.182.3.771-781.2000

Liew ATF, Foo YH, Gao Y, Zangoui P, Singh MK, Gulvady R, Kenney L. 2019. Single cell, super-resolution imaging reveals an acid pH-dependent conformational switch in SsrB regulates SPI-2. Elife 8. doi:10.7554/eLife.45311

Martin-Orozco N, Touret N, Zaharik ML, Park E, Kopelman R, Miller S, Finlay BB, Gros P, Grinstein S. 2006. Visualization of vacuolar acidification-induced transcription of genes of pathogens inside macrophages. Mol Biol Cell 17:498-510. doi:10.1091/mbc.e04-12-1096

McQuillen R, Xiao J. 2020. Insights into the Structure, Function, and Dynamics of the Bacterial Cytokinetic FtsZ-Ring. Annu Rev Biophys 49:309-341. doi:10.1146/annurev-biophys-121219-081703

Nagasawa H, Sakagami Y, Suzuki A, Suzuki H, Hara H, Hirota Y. 1989. Determination of the cleavage site involved in C-terminal processing of penicillin-binding protein 3 of Escherichia coli. J Bacteriol 171:5890-5893. doi:10.1128/jb.171.11.5890-5893.1989

Nelson DL, Kennedy EP. 1971. Magnesium transport in Escherichia coli. Inhibition by cobaltous ion. J Biol Chem 246:3042-3049.

Núñez-Hernández C, Tierrez A, Ortega AD, Pucciarelli MG, Godoy M, Eisman B, Casadesús J, García-del Portillo F. 2013. Genome expression analysis of nonproliferating intracellular Salmonella enterica serovar Typhimurium unravels an acid $\mathrm{pH}$-dependent PhoP-PhoQ response essential for dormancy. Infect Immun 81:154-165. doi:10.1128/IAI.01080-12

Osborne SE, Coombes BK. 2009. RpoE fine tunes expression of a subset of SsrB-regulated virulence factors in Salmonella enterica serovar Typhimurium. BMC Microbiol 9:45. doi:10.1186/1471-21809-45

Pérez-Morales D, Banda MM, Chau NYE, Salgado H, Martínez-Flores I, Ibarra JA, llyas B, Coombes BK, Bustamante VH. 2017. The transcriptional regulator SsrB is involved in a molecular switch controlling virulence lifestyles of Salmonella. PLoS Pathog 13:e1006497. doi:10.1371/journal.ppat.1006497 
Perkins TT, Davies MR, Klemm EJ, Rowley G, Wileman T, James K, Keane T, Maskell D, Hinton JCD, Dougan G, Kingsley RA. 2013. ChIP-seq and transcriptome analysis of the OmpR regulon of Salmonella enterica serovars Typhi and Typhimurium reveals accessory genes implicated in host colonization. Mol Microbiol 87:526-538. doi:10.1111/mmi.12111

Quinn HJ, Cameron ADS, Dorman CJ. 2014. Bacterial regulon evolution: distinct responses and roles for the identical OmpR proteins of Salmonella Typhimurium and Escherichia coli in the acid stress response. PLoS Genet 10:e1004215. doi:10.1371/journal.pgen.1004215

Radkov AD, Hsu Y-P, Booher G, VanNieuwenhze MS. 2018. Imaging Bacterial Cell Wall Biosynthesis. Annu Rev Biochem 87:991-1014. doi:10.1146/annurev-biochem-062917-012921

Rohs PDA, Bernhardt TG. 2021. Growth and Division of the Peptidoglycan Matrix. Annu Rev Microbiol 75:315-336. doi:10.1146/annurev-micro-020518-120056

Santander J, Roland KL, Curtiss R. 2008. Regulation of Vi capsular polysaccharide synthesis in Salmonella enterica serotype Typhi. J Infect Dev Ctries 2:412-420. doi:10.3855/jidc.154

Schägger H, von Jagow G. 1987. Tricine-sodium dodecyl sulfate-polyacrylamide gel electrophoresis for the separation of proteins in the range from 1 to $100 \mathrm{kDa}$. Anal Biochem 166:368-379. doi:10.1016/0003-2697(87)90587-2

Schindelin J, Arganda-Carreras I, Frise E, Kaynig V, Longair M, Pietzsch T, Preibisch S, Rueden C, Saalfeld S, Schmid B, Tinevez J-Y, White DJ, Hartenstein V, Eliceiri K, Tomancak P, Cardona A. 2012. Fiji: an open-source platform for biological-image analysis. Nat Methods 9:676-682. doi:10.1038/nmeth.2019

Schmieger H. 1972. Phage P22-mutants with increased or decreased transduction abilities. Mol Gen Genet 119:75-88. doi:10.1007/BF00270447

Singh SK, Parveen S, SaiSree L, Reddy M. 2015. Regulated proteolysis of a cross-link-specific peptidoglycan hydrolase contributes to bacterial morphogenesis. Proc Natl Acad Sci U S A 112:10956-10961. doi:10.1073/pnas.1507760112

Snavely MD, Gravina SA, Cheung TT, Miller CG, Maguire ME. 1991. Magnesium transport in Salmonella typhimurium. Regulation of mgtA and mgtB expression. J Biol Chem 266:824-829.

Steele-Mortimer 0. 2008. The Salmonella-containing vacuole: moving with the times. Curr Opin Microbiol 11:38-45. doi:10.1016/j.mib.2008.01.002

Szwedziak P, Lowe J. 2013. Do the divisome and elongasome share a common evolutionary past? Curr Opin Microbiol 16:745-51. doi:10.1016/j.mib.2013.09.003

Taylor RK, Hall MN, Enquist L, Silhavy TJ. 1981. Identification of OmpR: a positive regulatory protein controlling expression of the major outer membrane matrix porin proteins of Escherichia coli K-12. J Bacteriol 147:255-258. doi:10.1128/jb.147.1.255-258.1981

Typas A, Banzhaf M, Gross CA, Vollmer W. 2011. From the regulation of peptidoglycan synthesis to bacterial growth and morphology. Nat Rev Microbiol 10:123-36. doi:10.1038/nrmicro2677

Uzzau S, Figueroa-Bossi N, Rubino S, Bossi L. 2001. Epitope tagging of chromosomal genes in Salmonella. Proc Natl Acad Sci U S A 98:15264-15269. doi:10.1073/pnas.261348198

Verhoef C, Lugtenberg B, van Boxtel R, de Graaff P, Verheij H. 1979. Genetics and biochemistry of the peptidoglycan-associated proteins b and c of Escherichia coli K12. Mol Gen Genet 169:137-146. doi:10.1007/BF00271664

Vivero A, Baños RC, Mariscotti JF, Oliveros JC, García-del Portillo F, Juárez A, Madrid C. 2008. Modulation of horizontally acquired genes by the Hha-YdgT proteins in Salmonella enterica serovar Typhimurium. J Bacteriol 190:1152-1156. doi:10.1128/JB.01206-07

Vogel J, Papenfort K. 2006. Small non-coding RNAs and the bacterial outer membrane. Curr Opin Microbiol 9:605-11. doi:10.1016/j.mib.2006.10.006

Wang S-T, Kuo C-J, Huang C-W, Lee T-M, Chen J-W, Chen C-S. 2021. OmpR coordinates the expression of virulence factors of Enterohemorrhagic Escherichia coli in the alimentary tract of Caenorhabditis elegans. Mol Microbiol 116:168-183. doi:10.1111/mmi.14698

Worley MJ, Ching KH, Heffron F. 2000. Salmonella SsrB activates a global regulon of horizontally acquired genes. Mol Microbiol 36:749-761. doi:10.1046/j.1365-2958.2000.01902.x 